This item was submitted to Loughborough's Research Repository by the author.

Items in Figshare are protected by copyright, with all rights reserved, unless otherwise indicated.

\title{
A spatial productivity index in the presence of efficiency spillovers: evidence for U.S. banks, 1992-2015
}

PLEASE CITE THE PUBLISHED VERSION

https://doi.org/10.1016/j.ejor.2018.09.011

\section{PUBLISHER}

(C) Elsevier

\section{VERSION}

AM (Accepted Manuscript)

\section{PUBLISHER STATEMENT}

This paper was accepted for publication in the journal European Journal of Operational Research and the definitive published version is available at https://doi.org/10.1016/j.ejor.2018.09.011

\section{LICENCE}

CC BY-NC-ND 4.0

\section{REPOSITORY RECORD}

Glass, Anthony, and Karligash Glass. 2018. "A Spatial Productivity Index in the Presence of Efficiency Spillovers: Evidence for U.S. Banks, 1992-2015”. figshare. https://hdl.handle.net/2134/34899. 


\title{
A Spatial Productivity Index in the Presence of Efficiency Spillovers: Evidence for U.S. Banks, 1992 - 2015
}

\author{
Anthony J. Glass* and Karligash Kenjegalieva ${ }^{\dagger \dagger}$
}

July 2018

\begin{abstract}
We present the methodology for a new spatial decomposition of total factor productivity (TFP) growth. The relevant literature is underdeveloped as there is just one short study which proposes a partial spatial TFP growth decomposition. We develop this literature in four respects. The first two developments are methodological to go from a partial decomposition to a complete one. First, we augment the partial decomposition with a cost efficiency spillover growth component. Second, we introduce own and spillover allocative efficiency growth components. Third, we provide a more detailed coverage of the spatial decomposition of TFP growth. Fourth, in contrast to the traditional application to geographical areas (e.g., countries) in the relevant literature, we apply our decomposition using firm level data, which suggests that there can be an important role for spatial productivity analysis in OR. Our application is to large U.S. banks over the period 1992-2015. Among other things, we find for the average large U.S. bank that TFP growth since the financial crisis has become much more dependent on the bank itself and less so on spatial spillovers.
\end{abstract} Key words: (D) Productivity and competitiveness; Spatial total factor productivity; Productivity decomposition; Spatial cost and allocative efficiency growth; Large U.S. banks

${ }^{*}$ School of Business and Economics and Centre for Productivity and Performance, Loughborough University, Epinal Way, Loughborough, Leics, UK, LE11 3TU. Email: a.j.glass@lboro.ac.uk

${ }^{\dagger}$ School of Business and Economics and Centre for Productivity and Performance, Loughborough University, Epinal Way, Loughborough, Leics, UK, LE11 3TU. Email: k.a.kenjegalieva@lboro.ac.uk

${ }^{\ddagger}$ Corresponding author. The authors acknowledge the direction of the handling editor and excellent suggestions for improvement by three anonymous referees. The usual disclaimer applies. 


\section{Introduction}

Although there is a well-established non-spatial methodological literature on the decomposition of total factor productivity (TFP) growth (e.g., Diewert and Fox, 2017; O'Donnell, 2016; Sun et al., 2015; Oude Lansink et al., 2015; and Mukherjee et al., 2001) and a burgeoning literature on spatial stochastic frontier modeling (Druska and Horrace, 2004; Glass et al., 2013; 2016a; 2016b; Orea et al., 2018; and Tsionas and Michaelides, 2016), there is only one short paper by Glass et al. (2013) (GKPF from hereon) on the spatial decomposition of TFP growth. Our paper makes a number of contributions to this sparse literature as we extend the GKPF analysis in four respects. As the GKPF analysis is only a partial spatial extension of the non-spatial decomposition of generalized Malmquist TFP growth in Orea (2002), we use this non-spatial decomposition as a starting point. This non-spatial decomposition comprises a technical change component, returns to scale change and the change in technical efficiency. The GKPF decomposition comprises own and spillover technical change components, own and spillover returns to scale changes and the change in own efficiency. It therefore omits the change in the efficiency spillover, which is the reason why we refer to it as a partial spatial extension of Orea's decomposition. This omission is because at the time the method to calculate efficiency spillovers had not been developed, which has since been addressed by the methods that Glass et al. (2016a; 2016b) propose. Our first extension is therefore methodological and completes the GKPF spatial extension of Orea's decomposition by setting out the method to augment the GKPF decomposition with the change in the efficiency spillover.

A number of non-spatial decompositions of TFP growth also include an allocative efficiency change component (e.g., Bauer, 1990, and Kumbhakar and Lovell, 2000). Our second extension is once again methodological and involves extending this literature to the spatial case by further augmenting the GKPF decomposition with own and spillover allocative efficiency change components. Our third extension of the short communication in GKPF is our detailed coverage of the spatial decomposition of TFP growth and our fourth extension relates to our empirical application of the new methodology that we propose. Whereas the empirical application in GKPF is traditional as it applies spatial methods using data for geographical areas (cities, regions, etc.), we, on the other hand, apply our spatial decomposition of TFP growth using firm level data, which serves to highlight the future relevance of spatial efficiency and productivity analysis in OR. ${ }^{1}$

Our empirical application is to a spatial cost frontier for large U.S. banks over the period $1992-2015 .^{2}$ This is an interesting application as the sample includes the period pertaining to the financial crisis. Our application can therefore shed light on the implications of the tighter post-crisis regulatory regime for changes in the own and spillover cost and allocative efficiencies

\footnotetext{
${ }^{1}$ Specifically, GKPF apply their partial spatial TFP growth decomposition to a spatial aggregate production frontier for European countries.

${ }^{2}$ Outside the OR literature there are a small number of applications of spatial stochastic frontier modeling using firm level data (but not a spatial TFP growth decomposition). These applications of spatial frontier methods are exclusively in the economics literature and include Druska and Horrace (2004) who focus on Indonesian rice farms and Orea et al. (2018) who use data on Norwegian electricity distribution utilities. Our empirical application, however, represents the first case of spatial stochastic frontier modeling for banks.
} 
of large U.S. banks. ${ }^{3}$ That said, as our paper focuses on the presentation and demonstration of our new methodology for the spatial decomposition of TFP growth, our empirical application is rather general as it is pitched at the industry level. This is the case as we present mean spatial decompositions of TFP growth for our sample of large banks, and in the accompanying discussion the reasons we suggest to explain movements in spatial TFP growth are at the aggregate level (e.g., electronic banking becoming widespread practice in the industry in the second part of our study period). Given our application is pitched at the industry level, in further work there is scope for wider empirical application of our new methodology to more specific cases. One category of more specific cases in U.S. banking that would be worthwhile analyzing are key mergers and acquisitions, as there was a wave of consolidation in the industry following the Gramm-Leach-Bliley Act in November 1999. ${ }^{4}$

To apply our new spatial decomposition of TFP growth we must first estimate a spatial stochastic frontier model that contains, among other things, the spatial autoregressive (SAR) variable (i.e., the spatial lag of the dependent variable). We therefore provide a brief discussion of the evolution of the expanding methodological literature on spatial stochastic frontier modeling. Interestingly, the methodological literature on spatial stochastic frontier methods is beginning to mirror that for non-spatial stochastic frontier models. This is because spatial stochastic frontier studies can be split into two groups. The first group of studies contain the initial contributions on spatial stochastic frontier modeling and use a different approach to the one we utilize in this paper. This first group of studies estimate one-way spatial panel models and compute the efficiencies using the cross-sectional specific effects. The first such study is Druska and Horrace (2004). By extending the cross-sectional spatial error model in Kelejian and Prucha (1999) they develop a GMM stochastic frontier model with fixed effects. Using the fixed effects they calculate time-invariant efficiency by applying the Schmidt and Sickles (1984) efficiency estimator, which assumes a composed error structure with idiosyncratic error and time-invariant inefficiency components. GKPF is the same type of study as they use the fixed effects from a one-way SAR model to calculate time-varying efficiency using the method in Cornwell et al. (1990). ${ }^{5}$

The second group of spatial stochastic frontier studies, which is the group this paper belongs to, follows the vast majority of the non-spatial stochastic frontier literature by computing efficiency via distributional assumptions to distinguish between the idiosyncratic error and inefficiency components of the composed disturbance. One such study is Tsionas and Michaelides (2016) who develop a Bayesian estimator of what we refer to as a spatial inefficiency model, which is a form of spatial error stochastic frontier model as it contains a spatial lag of the inefficiency term. Two other studies that belong to this second group are by Glass et al. (2016a;

\footnotetext{
${ }^{3}$ The post-crisis tightening of the regulation of U.S. banks is the result of the Dodd-Frank regulatory reforms which came into being in 2010.

${ }^{4}$ The Gramm-Leach-Bliley Act repealed parts of the 1933 Glass-Steagall Banking Act allowing subsidiaries of U.S. banks to expand the range of their activities and engage in banking, securities and insurance, which represented the advent of 'broad banking' (Barth et al., 2000). The very nature of the repeal stimulated mergers to expand the scope of banking firms' product and service offerings.

${ }^{5}$ In spatial stochastic frontier modeling the spatial autocorrelated error (see Druska and Horrace, 2004) and the SAR variable (see GKPF) are endogenous, which is accounted for in the estimation.
} 
2016b). Both these studies propose a panel data spatial Durbin stochastic frontier model which is a SAR stochastic frontier model augmented with exogenous spatial lags of the independent variables. ${ }^{6}$ To minimize issues relating to convergence both these studies adopt a pseudo maximum likelihood (PML) estimator. In contrast to one-step full information ML (FML), PML estimates the model in steps. In Glass et al. (2016a) a two-step PML procedure is used, which involves estimating a non-frontier spatial Durbin model in the first step and in the second step the composed disturbance is split into the idiosyncratic error and time-varying inefficiency. This model has been extended by Glass et al. (2016b) to simultaneously include time-invariant and time-varying inefficiency components and via random effects is to the best of our knowledge the first spatial stochastic frontier model to account for unobserved heterogeneity. Given the extent of the heterogeneity across our sample of large U.S. banks, we use their modeling framework as the basis for the development of our spatial decomposition of TFP growth.

More specifically, we estimate a spatial Durbin stochastic frontier specification for three reasons. First, it is well-established that the spatial Durbin specification nests the SAR and spatial error specifications so a spatial Durbin model is robust to misspecification of the global spatial dependence (i.e., modeling spatial error autorcorrelation instead of the true SAR dependence and vice-versa). Second, although a spatial error/inefficiency specification and SAR and spatial Durbin specifications all account for global spatial dependence (1st order and higher order neighbor spatial interaction), with the spatial error/inefficiency specification the spillover elasticity relates to the disturbance/inefficiency. In contrast, and as we require for our spatial decomposition of TFP growth, the spillover elasticities from the SAR and spatial Durbin specifications can be related to the exogenous regressors. As a result of this property of the SAR and spatial Durbin specifications we obtain the spillover technical change and change in spillover returns to scale components of our spatial decomposition of TFP growth. Third, we favor the spatial Durbin specification over the SAR model because with the latter the ratio of the own and spillover elasticities (referred to in the spatial econometrics literature as direct and indirect elasticities, respectively) is the same for all exogenous variables, which is implausible. This is not the case with the spatial Durbin specification because of the presence of the spatial lags of the exogenous own regressors in the model, which are often found to be important determinants in spatial applications.

By way of an insight into our empirical findings, among other things, we find that in terms of allocative efficiency large U.S. banks responded appropriately to the financial crisis. This is because the crisis, which large U.S. banks played a key role in, marked the beginning of a period of annual increases in the change in the average allocative efficiency of large banks. Turning now to the structure of the remainder of this paper. In section 2 we set out the modeling framework which has three parts. In the first part we present the structural form of our random effects spatial Durbin stochastic cost frontier (SDCF) and we also briefly discuss our PML estimator. The second part shows how we use the reduced form of our model to compute cost efficiency

\footnotetext{
${ }^{6}$ Orea et al. (2018) also estimate a spatial Durbin stochastic frontier specification by making distributional assumptions to distinguish between the idiosyncratic error and inefficiency. As they note, however, the spatial variables in their model do not have an economic interpretation as they are used as predictors of omitted nonspatial variables, whereas in Glass et al. (2016a; 2016b) this is not the case so the spatial variables are causal.
} 
spillovers. In the third part we present the method for our spatial decomposition of TFP growth, which includes, among other things, the change in cost efficiency spillovers. Section 3 describes the data for the application. Section 4 reports and analyzes the empirical results and section 5 concludes.

\section{Modeling Framework}

\subsection{Panel Data Spatial Stochastic Frontier Model and an Overview of the Estimation Procedure}

The structural form of the spatial Durbin stochastic cost frontier (SDCF) model with random effects that we estimate, where variables are in log form, is as follows.

$$
\begin{aligned}
& c_{i t}=\alpha+T L\left(y_{i t}, p_{i t}, t\right)+\gamma^{\prime} z_{i t}+S T L\left(\sum_{j=1}^{N} w_{i j} y_{j t}, \sum_{j=1}^{N} w_{i j} p_{j t}\right)+\gamma_{s}^{\prime} \sum_{j=1}^{N} w_{i j} z_{j t}+ \\
& \quad \delta \sum_{j=1}^{N} w_{i j} c_{j t}+\kappa_{i}+v_{i t}+\eta_{i}+u_{i t} \\
& \kappa_{i} \sim N\left(0, \sigma_{\kappa}^{2}\right) \eta_{i} \sim N^{+}\left(0, \sigma_{\eta}^{2}\right) \quad v_{i t} \sim N\left(0, \sigma_{v}^{2}\right) u_{i t} \sim N^{+}\left(0, \sigma_{u}^{2}\right) .
\end{aligned}
$$

In each cross-section there are $N$ units indexed $i=1, \ldots, N$ that operate over $T$ periods indexed $t=1, \ldots, T$. Following the spatial econometrics literature and also the typical case that is encountered when using firm level data we have in mind cases where $N$ is large and $T$ is small. $T L\left(y_{i t}, p_{i t}, t\right)=\rho t+\frac{1}{2} \varsigma t^{2}+\zeta^{\prime} p_{i t}+\varphi^{\prime} y_{i t}+\frac{1}{2} p_{i t}^{\prime} \boldsymbol{\Theta} p_{i t}+\frac{1}{2} y_{i t}^{\prime} \boldsymbol{\Gamma} y_{i t}+p_{i t}^{\prime} \boldsymbol{\Psi} y_{i t}+\varrho^{\prime} p_{i t} t+\varpi^{\prime} y_{i t} t$ represents the variable returns to scale translog approximation of the log of the cost function technology. For the $i t h$ unit in period $t p_{i t}$ is the $(1 \times K)$ vector of observations for the input prices, which are indexed $k=1, \ldots, K . y_{i t}$ is the $(1 \times M)$ vector of observations for the outputs, which are indexed $m=1, \ldots, M, c_{i t}$ is an observation for total cost and $\alpha$ is the common intercept.

$\mathbf{W}_{\mathbf{N}}$ is the $(N \times N)$ exogenous matrix of non-negative constant spatial weights $w_{i j}$. The specification of $\mathbf{W}_{\mathbf{N}}$ represents, first, the spatial arrangement of the cross-sectional units and, second, the strength of the interaction between the units and as a result all the elements on the main diagonal of $\mathbf{W}_{\mathbf{N}}$ are set to zero as a unit cannot be in its own neighborhood set. $\mathbf{W}_{\mathbf{N}}$ is often populated using some measure of geographical proximity and must be specified a priori before estimation. Having specified $\mathbf{W}_{\mathbf{N}}$ we can construct $\sum_{j=1}^{N} w_{i j} c_{j t}$, which is the spatial lag of the dependent variable. This SAR variable is endogenous, which we account for in the estimation, and the SAR parameter $\delta \in\left(1 / r_{\min }, 1 / r_{\max }\right)$, where $r_{\min }$ and $r_{\max }$ are the most negative and most positive real characteristic roots of $\mathbf{W}_{\mathbf{N}}$, respectively. In our application $r_{\max }=1$ as we use a row-normalized specification of $\mathbf{W}_{\mathbf{N}}$. Note that in line with the spatial literature (e.g., Anselin, 2003), we refer to Eq. 1 as the structural form of our model as it includes the SAR variable as a regressor, whereas the SAR variable does not feature in the reduced form of our model that we use to, among other things, compute the cost efficiency spillovers. 
In our model specification $z_{i t}$ is a vector of observations for further non-spatial regressors, $\sum_{j=1}^{N} w_{i j} z_{j t}$ is its spatial lag and $\operatorname{STL}\left(\sum_{j=1}^{N} w_{i j} y_{j t}, \sum_{j=1}^{N} w_{i j} p_{j t}\right)$ is the spatial lag of $T L\left(y_{i t}, p_{i t}, t\right) . z_{i t}, \sum_{j=1}^{N} w_{i j} z_{j t}, S T L$ and also $\sum_{j=1}^{N} w_{i j} c_{j t}$ represent different variables that affect a firm's economic performance. In contrast to the SAR variable which accounts for endogenous global spatial dependence (1st order and higher order neighbor effects), $\sum_{j=1}^{N} w_{i j} z_{j t}$ and $S T L$ are exogenous and account for only local spatial dependence (1st order neighbor effects). We account for technical change through $T L\left(y_{i t}, p_{i t}, t\right)$ via a non-linear time trend by including $t$ and $t^{2}$ and by including the interactions $t y_{i t}$ and $t p_{i t}$ technical change is non-neutral. $\mathbf{W}_{\mathbf{N}} t$ and $\mathbf{W}_{\mathbf{N}} t^{2}$ are omitted from $S T L$ because when $\mathbf{W}_{\mathbf{N}}$ is row-normalized they are perfectly collinear with $t$ and $t^{2}$ in $T L\left(y_{i t}, p_{i t}, t\right)$ (i.e., $t=\mathbf{W}_{\mathbf{N}} t$ and $\left.t^{2}=\mathbf{W}_{\mathbf{N}} t^{2}\right)$. There are no such collinearity issues with the spatial lags of interaction terms that contain $t$ so these lags are retained.

In Eq. $1: \rho$ and $\frac{1}{2} \varsigma$ are regression parameters; $\zeta^{\prime}, \varphi^{\prime}, \varrho^{\prime}, \varpi^{\prime}, \gamma^{\prime}$ and $\gamma_{s}^{\prime}$ are vectors of regression parameters, where a subscript $s$ denotes a local spatial parameter; and $\frac{1}{2} \boldsymbol{\Theta}, \frac{1}{2} \boldsymbol{\Gamma}$ and $\boldsymbol{\Psi}$ are matrices of the regression parameters $\frac{1}{2} \theta, \frac{1}{2} \tau$ and $\psi$, respectively. We also estimate the corresponding local spatial parameters for $S T L$ with the exception of $\rho_{s}$ and $\frac{1}{2} \varsigma_{s}$ due to the aforementioned collinearity of $\mathbf{W}_{\mathbf{N}} t$ and $\mathbf{W}_{\mathbf{N}} t^{2}$. From the properties of the translog functional form (Christensen et al., 1973), Eq. 1 is twice differentiable with respect to an output, an input price and the spatial lags of an output and input price. The associated Hessians are symmetric because of the symmetry restrictions that are placed on the matrices of parameters (e.g., $\frac{1}{2} \tau_{1 M}=\frac{1}{2} \tau_{M 1}$ in $\frac{1}{2} \boldsymbol{\Gamma}$ ).

Our model specification is characterized by a four component error structure, $\varepsilon_{i t}^{*}=\varepsilon_{i}+\varepsilon_{i t}=$ $\kappa_{i}+v_{i t}+\eta_{i}+u_{i t}$, where $\varepsilon_{i}=\kappa_{i}+\eta_{i}$ is the time-invariant component and $\varepsilon_{i t}=v_{i t}+u_{i t}$ is the time-varying component. Since our estimator of Eq. 1 rests on $\kappa_{i}, v_{i t}, \eta_{i}$ and $u_{i t}$ being independently distributed we account for unobserved heterogeneity using random effects. We do not account for unobserved heterogeneity in our model using fixed effects as the time-varying idiosyncratic errors will not be independently distributed as they will be correlated with the fixed effects. In Eq. $1 v_{i t}$ is the idiosyncratic error and as is standard when modeling unobserved heterogeneity using random effects, the unit specific effect, $\kappa_{i}$, is a time-invariant random error. $\eta_{i}$ is time-invariant inefficiency, $u_{i t}$ is time-varying inefficiency and both $\eta_{i}$ and $u_{i t}$ are bounded in the interval $[0,1]$. Both $\eta_{i}$ and $u_{i t}$ are also assumed to have half-normal distributions which is a common distributional assumption for inefficiency in the stochastic frontier literature (e.g., Bos et al., 2009, and Greene, 2004). Our estimation procedure, however, is sufficiently general to accommodate alternative distributional assumptions for $u_{i t}$ and $\eta_{i}$.

Testing the appropriateness of the error structure in our model specification for an empirical application involves applying the one-sided hypothesis test in Gouriéroux et al. (1982) to test for the presence of each of the four error components $(\kappa, v, \eta$ and $u)$. The test statistic has an asymptotic distribution that is a mixture of chi-squared distributions, $\frac{1}{2} \chi^{2}(0)+\frac{1}{2} \chi^{2}(1)$. For $G \in\{\kappa, v, \eta, u\}$ rejection of the null, $\widehat{\sigma}_{G}^{2}=0$, in favor of the alternative hypothesis, $\widehat{\sigma}_{G}^{2}>0$, constitutes evidence of the presence of the error component. In an empirical setting both of the nulls for the inefficiency components may not be rejected so the model specification in Eq. 1 has the appealing feature that it nests other models. For example, failure to reject the absence of 
$\eta$ would lead to Eq. 1 collapsing to the SDCF extension of the non-spatial true random effects frontier model (Greene, 2005).

To put our model into context we relate Eq. 1 to other models in the stochastic frontier literature. By omitting $S T L\left(\sum_{j=1}^{N} w_{i j} y_{j t}, \sum_{j=1}^{N} w_{i j} p_{j t}\right), \gamma_{s}^{\prime} \sum_{j=1}^{N} w_{i j} z_{j t}$ and $\delta \sum_{j=1}^{N} w_{i j} c_{j t}$ from Eq. 1 we obtain the non-spatial counterpart of our model, which is the model that Tsionas and Kumbhakar (2014), Colombi et al. (2014), Filippini and Greene (2016), Badunenko and Kumbhakar (2016; 2017) and Kumbhakar et al. (2014) consider. Alternatively, by omitting the local spatial terms from Eq. 1 (i.e., $S T L\left(\sum_{j=1}^{N} w_{i j} y_{j t}, \sum_{j=1}^{N} w_{i j} p_{j t}\right)$ and $\left.\gamma_{s}^{\prime} \sum_{j=1}^{N} w_{i j} z_{j t}\right)$ the model becomes a SAR stochastic frontier specification. We, however, retain these local spatial variables because, as will become apparent, in our application to large U.S. banks some of the local spatial covariates are important determinants.

We now turn to a brief overview of our estimation procedure for Eq. 1. For more details of this estimation procedure see Glass et al. (2016b). For the non-spatial counterpart of Eq. 1 Tsionas and Kumbhakar (2014) develop a one-step Bayesian estimator and Colombi et al. (2014) estimate this non-spatial model using a one-step maximum likelihood (ML) approach (i.e., full information maximum likelihood, FML). Due to concerns about the sensitivity of the Bayesian approach to the choice of informative priors for the main objects of the estimation and concerns about the empirical tractability of the FML procedure, Filippini and Greene (2016) and Badunenko and Kumbhakar (2016; 2017) estimate this non-spatial model using one-step simulated ML. Eq. 1 is of course more complex than its non-spatial counterpart because of the presence of the additional SAR term. For this reason we employ a pseudo maximum likelihood (PML) estimation procedure, which is simpler than a one-step estimator as it estimates the model in steps. ${ }^{7}$ Multi-step estimation of the type of model we use has practical benefits as its facilitates model convergence and our estimator is consistent. In particular, our PML estimator of Eq. 1 maximizes three log-likelihood functions, one for each step. Step 1 estimates the nonfrontier random effects spatial Durbin model, which distinguishes between the time-invariant and time-varying components of the composed error. See Glass et al. (2016b) for details on how a random effects spatial Durbin stochastic frontier model such as Eq. 1 is transformed into the corresponding non-frontier model for step 1. Step 2 splits the time-varying error component from step 1 into its constituent parts, $v_{i t}$ and $u_{i t}$, and step 3 splits the time-invariant error from step 1 into $\kappa_{i}$ and $\eta_{i}$.

Putting our estimator into context, the practical appeal of our PML routine comes at a cost as there is a loss of statistical efficiency when our model is estimated in steps and the error components must be homoscedastic. To estimate an even more complex spatial stochastic frontier with heteroscedastic error components one cannot therefore use PML. See Gude et al. (2017) for this type of spatial stochastic frontier model, where in their model variables are allowed to affect the mean of inefficiency. Notwithstanding the importance of the costs and benefits of different estimators of spatial stochastic frontier models, we do pursue these issues any further in this paper as our interest centres on development of the methodology for the spatial decomposition of TFP growth.

\footnotetext{
${ }^{7}$ See Kumbhakar et al. (2014) for the corresponding non-spatial PML estimator.
} 


\subsection{Elasticities, Own Cost Efficiencies and Cost Efficiency Spillovers}

It is now well-established for models that contain the SAR variable and are in log form that the fitted coefficients on the exogenous variables are not elasticities. This is because the elasticity of an exogenous variable is a function of the SAR parameter. It is therefore now standard in spatial econometrics to calculate direct, indirect and total elasticities using the regression parameters. A direct elasticity is interpreted in the same way as an elasticity from a non-spatial model, although a direct elasticity takes into account feedback effects which occur via the spatial multiplier matrix. Feedback is the effect of a change in an independent variable for a particular unit which reverberates back to the same unit's dependent variable through its effect on the dependent variables of the other units in the sample. An indirect elasticity can be calculated in two ways yielding the same numerical value. This leads to two interpretations of an indirect elasticity: (i) average change in the dependent variable of all the other units in the sample following a change in an independent variable for one particular unit; or (ii) average change in the dependent variable for a particular unit following a change in an independent variable for all the other units in the sample. The total elasticity is the sum of the direct and indirect elasticities.

Calculation of the direct, indirect and total elasticities and the cost efficiency spillovers is based on the reduced form of the spatial model. To rewrite Eq. 1 in its reduced form we first rewrite Eq. 1 as Eq. 2 by dropping the $i$ subscripts to denote vectors of successively stacked cross-sectional observations.

$$
c_{t}=\alpha \iota+T L\left(y_{t}, p_{t}, t\right)+\gamma^{\prime} z_{t}+S T L\left(\mathbf{W}_{\mathbf{N}} y_{t}, \mathbf{W}_{\mathbf{N}} p_{t}\right)+\gamma_{s}^{\prime} \mathbf{W}_{\mathbf{N}} z_{t}+\delta \mathbf{W}_{\mathbf{N}} c_{t}+\kappa+v_{t}+\eta+u_{t},
$$

where $\iota$ denotes the $(N \times 1)$ vector of ones and everything else is as previously defined for Eq. 1 . We then in Eq. 3 take the $\delta \mathbf{W}_{\mathbf{N}} c_{t}$ term in Eq. 2 to the left-hand side which gives $\left(\mathbf{I}_{\mathbf{N}}-\delta \mathbf{W}_{\mathbf{N}}\right) c_{t}$, where $\mathbf{I}_{\mathbf{N}}$ denotes the $(N \times N)$ identity matrix.

$$
\left(\mathbf{I}_{\mathbf{N}}-\delta \mathbf{W}_{\mathbf{N}}\right) c_{t}=\alpha \iota+T L\left(y_{t}, p_{t}, t\right)+\gamma^{\prime} z_{t}+S T L\left(\mathbf{W}_{\mathbf{N}} y_{t}, \mathbf{W}_{\mathbf{N}} p_{t}\right)+\gamma_{s}^{\prime} \mathbf{W}_{\mathbf{N}} z_{t}+\kappa+v_{t}+\eta+u_{t}
$$

Finally, we obtain the reduced form of Eq. 1 in Eq. 4 by taking $\left(\mathbf{I}_{\mathbf{N}}-\delta \mathbf{W}_{\mathbf{N}}\right)$ in Eq. 3 to the right-hand side:

$$
c_{t}=\left(\mathbf{I}_{\mathbf{N}}-\delta \mathbf{W}_{\mathbf{N}}\right)^{-1}\left(\begin{array}{c}
\alpha \iota+T L\left(y_{t}, p_{t}, t\right)+\gamma^{\prime} z_{t}+S T L\left(\mathbf{W}_{\mathbf{N}} y_{t}, \mathbf{W}_{\mathbf{N}} p_{t}\right)+ \\
\gamma_{s}^{\prime} \mathbf{W}_{\mathbf{N}} z_{t}+\kappa+v_{t}+\eta+u_{t}
\end{array}\right),
$$

where in the spatial literature $\left(\mathbf{I}_{\mathbf{N}}-\delta \mathbf{W}_{\mathbf{N}}\right)^{-1}$ is referred to as the spatial multiplier matrix.

We set out the approach to calculate the direct, indirect and total elasticities for a variable in the context of a first order output, which we denote $y_{m, t}$. From the local spatial counterpart of Eq. 1 (i.e., Eq. 1 with the SAR variable omitted), which would only capture first order neighbor effects, if we use mean adjusted data all the fitted parameters on the first order variables from 
this local spatial model are elasticities at the sample mean. This is because at the sample mean the own and local spatial quadratic and interaction terms are zero. Applying this to the reduced form of our SDCF in Eq. 4, the fitted $\varphi_{m}$ and $\varphi_{s, m}$ parameters for $y_{m, t}$ and $\mathbf{W}_{\mathbf{N}} y_{m, t}$, respectively, can be used to directly calculate the direct, indirect and total elasticities for $y_{m, t}$ at the sample mean. ${ }^{8}$ Whereas the first order direct, indirect and total output, input price and time trend parameters are elasticities at the sample mean, this is not the case for other points in the sample i.e., outside the sample mean. To obtain direct, indirect and total output, input price and time trend elasticities outside the sample mean, we must apply the approach for a non-spatial translog function to our spatial setting and use, among other things, the first order, quadratic and interaction direct, indirect and total parameters.

Differentiating Eq. 4 with respect to $y_{m, t}$ as follows yields a matrix of direct and indirect elasticities for each unit, where the right-hand side of Eq. 6 is independent of the time index.

$$
\begin{aligned}
{\left[\frac{\partial c}{\partial y_{m, 1}}, \cdots, \frac{\partial c}{\partial y_{m, N}}\right]_{t} } & =\left[\begin{array}{ccc}
\frac{\partial c_{1}}{\partial y_{m, 1}} & \cdots & \frac{\partial c_{1}}{\partial y_{m, N}} \\
\vdots & \ddots & \vdots \\
\frac{\partial c_{N}}{\partial y_{m, 1}} & \cdots & \frac{\partial c_{N}}{\partial y_{m, N}}
\end{array}\right]_{t} \\
& =\left(\mathbf{I}_{\mathbf{N}}-\delta \mathbf{W}_{\mathbf{N}}\right)^{-1}\left[\begin{array}{ccc}
\varphi_{m} & \cdots & w_{1 N} \varphi_{s, m} \\
\vdots & \ddots & \vdots \\
w_{N 1} \varphi_{s, m} & \cdots & \varphi_{m}
\end{array}\right]
\end{aligned}
$$

Since Eq. 6 yields different direct and indirect elasticities for each unit, to facilitate interpretation we report the mean direct elasticity (average of the diagonal elements of Eq. 6) and the mean indirect elasticity. (This latter average spillover elasticity to a unit is the average row sum of the off-diagonal elements of Eq. 6 and is numerically the same as the average spillover elasticity from a unit which is the average column sum of the off-diagonal elements of Eq. 6). For $t$ and $t^{2}$, whose spatial lags are omitted from Eq. 1, the mean direct, indirect and total parameters are calculated using Eq. 6 but with the off-diagonal elements in the second matrix set equal to zero by construction. In these cases the spillover is solely due to the SAR term. To compute the $t$-statistics for the mean direct, indirect and total parameters we use Monte Carlo simulation of the distributions of these means.

Having applied the Battese and Coelli (1988) (BC from hereon) panel data inefficiency estimator to the fitted structural form of the model in Eq. 1 to obtain the estimates of the own time-invariant and time-varying cost inefficiencies $\left(\widehat{\eta}_{i}\right.$ and $\widehat{u}_{i t}$, respectively), which involves predicting $\eta_{i}$ conditional on $\varepsilon_{i}$ and $u_{i t}$ conditional on $\varepsilon_{i t}$ (i.e., $\widehat{\eta}_{i}=\mathrm{E}\left(\eta_{i} \mid \varepsilon_{i}\right)$ and $\left.\widehat{u}_{i t}=\mathrm{E}\left(u_{i t} \mid \varepsilon_{i t}\right)\right)$,

\footnotetext{
${ }^{8}$ In line with our demonstration of the method to calculate the direct, indirect and total elasticities for a first order output at the sample mean, in our application to large U.S. banks we report elasticities at the sample mean. This is the standard way of presenting a fitted translog model as it is a much more concise way of reporting elasticities than presenting elasticities outside the sample mean. For a spatial model such as our SDCF there is a greater need to present elasticities at the sample mean for conciseness because, as we noted above, we report three types of elasticities as opposed the standard type from a non-spatial model. As will become apparent, we of course use direct, indirect and total elasticities outside the sample mean to compute the components of our spatial TFP index over our sample.
} 
we use the reduced form of our model in Eq. 4 to estimate the direct, indirect and total cost efficiencies. Direct efficiency for a unit is interpreted in the same way as own efficiency from a non-spatial model but, in contrast, comprises own efficiency plus efficiency feedback. An example of efficiency feedback is the effect of a change in a unit's independent variable, which affects the dependent variables and efficiencies of the unit's 1st and higher order neighbors and then through the spatial multiplier matrix this effect partially rebounds back to the dependent variable and efficiency of the unit that initiated the process. As is the case for an indirect elasticity, the asymmetric indirect efficiency for a unit can be interpreted in two ways: (i) the sum of the efficiency spillovers to a unit from all the other units in the sample; and (ii) the sum of efficiency spillovers from a unit to all the other units in the sample. Here we use the first measure of the indirect spillover efficiency as our spatial decomposition of TFP growth focuses on how the system/network that an individual unit is part of affects the unit, as opposed to how an individual unit contributes to the system/network. In the same way as a total elasticity is calculated, a unit's total efficiency is the sum of its direct and indirect efficiencies. Due to there being two asymmetric indirect efficiencies for a unit, there are two asymmetric total efficiencies for each unit. In line with the indirect spillover efficiency measure we use, our total efficiency measure is calculated using the sum of the efficiency spillovers that are transmitted to a unit. It should be emphasized, however, that our approach can easily be modified so that the underlying idea of our spatial decomposition of TFP growth can be the basis of a spatial decomposition that focuses on a unit's contribution to the system/network. This would involve computing the spillover components of the decomposition using the spill-outs from a unit rather than, as we do, using the spill-ins to a unit.

Glass et al. (2016a) adopt a similar approach to one we employ, although they compute relative direct, indirect and total efficiencies from the reduced form of their spatial frontier, whereas we compute absolute direct, indirect and total efficiencies. Their approach to compute relative direct, indirect and total efficiencies, however, is sensitive to the best performance in each period being an outlier, which one would need to adjust for. Also, we do not know whether the relative indirect spillover efficiencies are substantive. This is because all the actual absolute indirect efficiencies that are used to compute the relative indirect efficiencies may not be substantive as they all could be similarly small in magnitude. We therefore follow Glass et al. (2016b) in the first instance by computing absolute measures of direct, indirect and total cost efficiencies to examine if the indirect efficiency spillovers are indeed substantive. In the second instance we extend their exposition by using the growth of these absolute direct, indirect and total cost efficiencies as part of our new spatial decomposition of TFP growth. Other components that we introduce to construct our new spatial decomposition are the growth in direct, indirect and total allocative efficiencies, which we discuss in detail in the next subsection.

To calculate the absolute direct, indirect and total time-invariant and time-varying cost efficiencies from the reduced form model in Eq. 4 we must first transform the estimates of the own time-invariant and own time-varying cost inefficiencies from the structural form in Eq. 1 into the corresponding own efficiency measures. We refer to the own time-invariant and own time-varying cost efficiencies as own net time-invariant and own net time-varying efficiencies (denoted as $N_{I} E_{i}$ 
and $N V E_{i t}$, respectively) to signify that the former is net of time-variance and the latter is net of time-invariance. As our model in Eq. 1 is in log form and using the aforementioned BC efficiency estimator for panel data $N V E_{i t}=\exp \left(u_{i t}\right)$ and $N I E_{i}=\exp \left(\eta_{i}\right)$ are the estimates of the own net efficiencies. Using these own net efficiencies we compute the estimate of the combined efficiency, which we refer to as gross time-varying efficiency $\left(G V E_{i t}=\exp \left(\eta_{i}+u_{i t}\right)=N I E_{i} * N V E_{i t}\right){ }^{9}$

Own $N I E_{i}, N V E_{i t}$ and $G V E_{i t}$ measures do not include any efficiency spillovers. Using the reduced form model in Eq. 4 these own net and gross efficiency measures can be related to absolute direct, indirect and total net and gross efficiencies, where these direct, indirect and total measures are partially/entirely made up of efficiency spillovers. To see this relationship between the own net and gross efficiencies and the absolute direct, indirect and total net and gross measures recognize from Eq. 4 that $\left(\mathbf{I}_{\mathbf{N}}-\delta \mathbf{W}_{\mathbf{N}}\right)^{-1} \eta=\eta_{T o}^{T o t}$ and $\left(\mathbf{I}_{\mathbf{N}}-\delta \mathbf{W}_{\mathbf{N}}\right)^{-1} u_{t}=$ $u_{t, T o}^{T o t}$ are $(N \times 1)$ vectors of absolute total $(T o t)$ time-invariant and time-varying inefficiencies, respectively. The subscript $T o$ in these terms denotes that the inefficiency spillovers used in the calculation of these absolute total inefficiency vectors are inefficiency spillovers which come to the $i t h$ unit from all the $j t h$ units in the sample for $i \neq j$. Based on own $N V E_{i t}=\exp \left(u_{i t}\right)$ and own $N I E_{i}=\exp \left(\eta_{i}\right)$ from the above structural model in Eq. 1 , the $(N \times 1)$ vectors of absolute total efficiencies that directly correspond to the above vectors of absolute total time-invariant and total time-varying inefficiencies $\left(\eta_{T o}^{T o t}\right.$ and $\left.u_{t, T o}^{T o t}\right)$ are $\left(\mathbf{I}_{\mathbf{N}}-\delta \mathbf{W}_{\mathbf{N}}\right)^{-1} \exp (\eta)=N I E_{T o}^{T o t}$ and $\left(\mathbf{I}_{\mathbf{N}}-\delta \mathbf{W}_{\mathbf{N}}\right)^{-1} \exp \left(u_{t}\right)=N V E_{t, T o}^{T o t}$. In similar vein, based on from above own $G V E_{i t}$ being given by $N I E_{i} * N V E_{i t}=\exp \left(\eta_{i}+u_{i t}\right)$, the $(N \times 1)$ vector of absolute total gross efficiencies that corresponds to absolute $N I E_{T o}^{T o t}$ and $N V E_{t, T o}^{T o t}$ is $\left(\mathbf{I}_{\mathbf{N}}-\delta \mathbf{W}_{\mathbf{N}}\right)^{-1} \exp \left(\eta+u_{t}\right)=G V E_{t, T o}^{T o t}$. In terms of interpretation, one can think of own $N I E_{i}, N V E_{i t}$ and $G V E_{i t}$ as being different measures of a firm's internal efficiency. $N I E_{T o}^{T o t}, N V E_{t, T o}^{T o t}$ and $G V E_{t, T o}^{T o t}$, on the other hand, can be interpreted as different collective measures of a firm's internal and external efficiency or put another way different measures of a firm's system/network efficiency.

$G V E_{t, T o}^{T o t}$ can be written in the following form and similar expressions can be used to represent the vectors $N I E_{T o}^{T o t}$ and $N V E_{t, T o}^{T o t}$.

$$
\left(\mathbf{I}_{\mathbf{N}}-\delta \mathbf{W}_{\mathbf{N}}\right)^{-1}\left(\begin{array}{c}
G V E_{1} \\
\vdots \\
G V E_{N}
\end{array}\right)_{t}=\left(\begin{array}{ccccc}
G V E_{11}^{D i r} & + & \cdots & + & G V E_{1 N}^{I n d} \\
\vdots & + & \ddots & + & \vdots \\
G V E_{N 1}^{I n d} & + & \cdots & + & G V E_{N N}^{D i r}
\end{array}\right)_{t}=\left(\begin{array}{c}
G V E_{T o, 1}^{T o t} \\
\vdots \\
G V E_{T o, N}^{T o t}
\end{array}\right)_{t}
$$

where $G V E_{i j t}^{D i r}$ on the main diagonal denotes the absolute direct $G V E$ for the ith unit in period

\footnotetext{
${ }^{9}$ In the literature on the corresponding non-spatial model own $G V E$ is referred to as overall time-varying efficiency (Colombi et al., 2014; Kumbhakar et al., 2014; Filippini and Greene, 2016). We, however, refer to it as own gross time-varying efficiency because based on the terminology used in the spatial econometrics literature having computed own $G V E$ we proceed to compute direct, indirect and total GVE (see Glass et al., 2016b). This avoids referring to total $G V E$ as the total overall time-varying efficiency, which would be confusing. Consequently, we refer to the time-invariant and time-varying efficiencies that are the constituent parts of own $G V E$ as own net efficiencies. Own NIE, NVE and GVE should also not be confused with the net and gross efficiencies in Coelli et al. (1999) as the interpretations of net and gross in their set-up are entirely different.
} 
$t$; $G V E_{i j t}^{I n d}$ is the absolute indirect $G V E$ spillover to the $i t h$ unit from the $j t h$ unit for $i \neq j$; and $G V E_{t, T o}^{I n d}=\sum_{j=1}^{N} G V E_{i j t}^{I n d}$ is the sum of the absolute indirect $G V E$ spillovers to the $i t h$ unit from all the $j$ th units for $i \neq j$. Eq. 7 therefore demonstrates that the $(N \times 1)$ vector $G V E_{t, T o}^{T o t}$ can be additively decomposed into the $(N \times 1)$ vectors $G V E_{t}^{D i r}$ and $G V E_{t, T o}^{I n d}$. Using the same approach $N I E_{T o}^{T o t}$ can be additively decomposed into the vectors $N I E^{D i r}$ and $N I E_{T o}^{I n d}$, and $N V E_{t, T o}^{T o t}$ can be additively decomposed into the vectors $N V E_{t}^{D i r}$ and $N V E_{t, T o}^{I n d}$. If $\mathbf{W}_{\mathbf{N}}$ is asymmetric, which is the case in our empirical application and is typically the case in the empirical spatial literature, $\left(\mathbf{I}_{\mathbf{N}}-\delta \mathbf{W}_{\mathbf{N}}\right)^{-1}$ will be asymmetric. This results in $G V E_{i j t}^{I n d} \neq G V E_{j i t}^{I n d}, N V E_{i j t}^{I n d} \neq N V E_{j i t}^{I n d}$ and $N I E_{i j}^{I n d} \neq N I E_{j i}^{I n d}$, which indicates that there are asymmetric indirect $G V E, N V E$ and NIE spillovers that permeate to and from a unit. ${ }^{10}$

As own NIE, NVE and GVE are the standard type of efficiencies from a stochastic frontier model they are bounded in the interval $[0,1]$. The lower bound of the direct, indirect and total NIE, NVE and GVE scores from the reduced form of our model is of course also 0. Other than that direct, indirect and total NIE, NVE and GVE are unbounded. This in no way precludes these efficiencies from being incorporated into the spatial decomposition of TFP growth that we propose because our direct, indirect and total NIE, NVE and GVE measures are easily interpretable as they are percentages. This is because direct, indirect and total $N I E, N V E$ and $G V E$ are scaled own $N I E, N V E$ and GVE. As a result these direct, indirect and total efficiencies have a simple interpretation as they are relative to the own NIE, $N V E$ and $G V E$ benchmarks. If the magnitude of the efficiency spillover is sufficiently large the direct/indirect/total NIE, NVE or GVE score will be greater than 1. If this is the case the efficiency spillover has pushed the unit beyond the best practice frontier for the relevant own efficiency from Eq. 1. The intuition here is that irrespective of whether the efficiency spillover leads to a direct/indirect/total $N I E, N V E$ or $G V E$ score greater than, equal to or less than 1, the spillover acts as an efficiency performance multiplier. One possibility therefore is that a unit's own efficiency performance (internal efficiency) is relatively low but due to a large efficiency spillover (external efficiency), the unit's collective internal and external efficiency performance (system/network efficiency) is relatively better than its internal efficiency.

We can succinctly summarize the novel idea of an efficiency score greater than 1 from the reduced form of a spatial stochastic frontier model using the illustrative case in figure 1. Rather than use a cost technology to depict this idea we revert to the standard textbook single input

\footnotetext{
${ }^{10}$ As our new spatial TFP growth decomposition focuses on how the system/network that an individual unit is part of affects the unit, we are interested in the indirect cost efficiency spillovers that gravitate across space to an individual unit. The reduced form model in Eq. 4 also yields indirect cost efficiency spillovers that gravitate in the opposite direction from a unit, which can be used to construct our spatial TFP growth decomposition in the alternative setting of a unit's contribution to the system/network. The $(1 \times N)$ absolute total $G V E$ vector that relates to the contribution of a unit to the system/network is made up of the column sums of the components in Eq. 7, which we denote $G V E_{t, \text { From }}^{T o t^{\prime}}=\left(G V E_{\text {From }, 1}^{T o t}, G V E_{\text {From }, 2}^{\text {Tot }}, \ldots, G V E_{\text {From }, N}^{\text {Tot }}\right)_{t}$. Here the subscript From indicates that the absolute indirect $G V E$ spillovers used in the calculation of $G V E_{t, F r o m}^{T o t^{\prime}}$ are the $G V E$ spillovers that gravitate from the $i t h$ unit to the $j t h$ unit for $i \neq j$. The sum of these absolute indirect $G V E$ spillovers to the $j$ th unit from all the $i t h$ units is given by $G V E_{t, F r o m}^{I n d}=\sum_{i=1}^{N} G V E_{i j t}^{I n d}$ for $i \neq j$. Using the expressions for $N I E_{T o}^{T o t}$ and $N V E_{t, T o}^{T o t}$ that correspond to Eq. 7 we can obtain the $(1 \times N)$ vectors $N I E_{\text {From }}^{T o t^{\prime}}$ and $N V E_{t, F r o m}^{T o t^{\prime}}$, and we can also additively decompose these vectors, as we have done for $G V E_{t, F r o m}^{T o t^{\prime}}$, into their absolute direct and indirect components.
} 


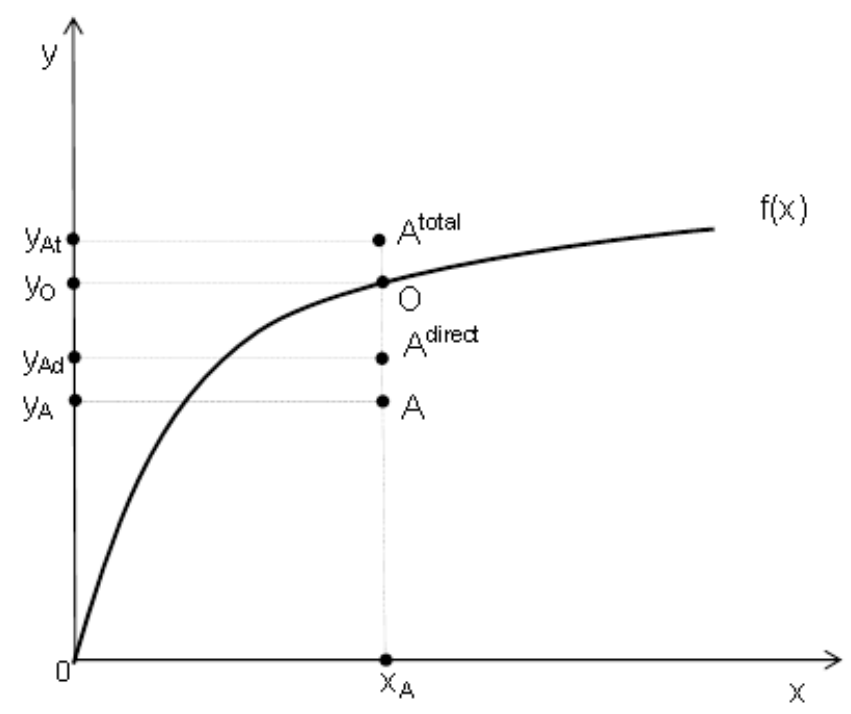

Figure 1: An illustrative case of own, direct, indirect and total efficiencies

$(x)$-single output $(y)$ production technology. The figure represents own, direct, indirect and total NIE, NVE or GVE, where to simplify the discussion we do not distinguish between NIE, NVE or GVE and just refer to efficiency. The productive unit that we consider operates at point $\mathrm{A}$ with an own efficiency of $y_{A} / y_{O}$, where $y=f(x)$ represents the own best practice frontier as defined by the structural form of the spatial stochastic frontier model. Its direct efficiency from the reduced form of the spatial stochastic frontier is $y_{A d} / y_{O}$ and the feedback efficiency component of this direct efficiency is $\left(y_{A d}-y_{A}\right) / y_{O}$, which in this illustrative case is positive. Again from the reduced form, indirect efficiency is $\left(y_{A t}-y_{A d}\right) / y_{O}$ and total efficiency is $y_{A t} / y_{O}$, where in this case the latter is greater than 1 (as indicated by $\mathrm{A}^{\text {total }}$ being above the own best practice frontier).

\subsection{Spatial TFP Growth with Spatial Cost and Allocative Efficiency Change Components}

The starting point for the calculation of the components of the spatial TFP index that we propose are the estimated direct, indirect and total models, which have the following forms. See Glass et al. (2015) for details on how the presence of the SAR variable in a model gives rise to direct, indirect and total models (referred to in their paper as internal, external and total models).

$$
\begin{aligned}
& c_{i t}^{D i r}=\rho^{D i r} t_{i}+\frac{1}{2} \varsigma^{D i r} t_{i}^{2}+\zeta^{D i r^{\prime}} p_{i t}+\varphi^{D i r^{\prime}} y_{i t}+\frac{1}{2} p_{i t}^{\prime} \Theta^{\text {Dir }} p_{i t}+\frac{1}{2} y_{i t}^{\prime} \boldsymbol{\Gamma}^{\mathbf{D i r}} y_{i t}+ \\
& p_{i t}^{\prime} \boldsymbol{\Psi}^{\mathbf{D i r}} y_{i t}+\varrho^{D i r^{\prime}} p_{i t} t_{i}+\varpi^{D i r^{\prime}} y_{i t} t_{i}+\gamma^{D i r^{\prime}} z_{i t}+\eta_{i}^{D i r}+u_{i t}^{D i r}
\end{aligned}
$$




$$
\begin{aligned}
& c_{i t}^{I n d}=\rho^{I n d} t_{i}+\frac{1}{2} \varsigma^{I n d} t_{i}^{2}+\zeta^{I n d^{\prime}} p_{i t}+\varphi^{I n d^{\prime}} y_{i t}+\frac{1}{2} p_{i t}^{\prime} \Theta^{\text {Ind }} p_{i t}+\frac{1}{2} y_{i t}^{\prime} \Gamma^{\text {Ind }} y_{i t}+ \\
& p_{i t}^{\prime} \Psi^{\text {Ind }} y_{i t}+\varrho^{I n d^{\prime}} p_{i t} t_{i}+\varpi^{I n d^{\prime}} y_{i t} t_{i}+\gamma^{I n d^{\prime}} z_{i t}+\eta_{i, T o}^{I n d}+u_{i t, T o}^{I n d}, \\
& c_{i t}^{T o t}=\rho^{T o t} t_{i}+\frac{1}{2} \varsigma^{T o t} t_{i}^{2}+\zeta^{T o t^{\prime}} p_{i t}+\varphi^{T o t^{\prime}} y_{i t}+\frac{1}{2} p_{i t}^{\prime} \Theta^{\text {Tot }} p_{i t}+\frac{1}{2} y_{i t}^{\prime} \Gamma^{\mathbf{T o t}} y_{i t}+ \\
& p_{i t}^{\prime} \boldsymbol{\Psi}^{\text {Tot }} y_{i t}+\varrho^{T o t^{\prime}} p_{i t} t_{i}+\varpi^{T o t^{\prime}} y_{i t} t_{i}+\gamma^{T o t^{\prime}} z_{i t}+\eta_{i, T o}^{T o t}+u_{i t, T o}^{T o t} .
\end{aligned}
$$

where an indirect elasticity measures the responsiveness of $c_{i t}^{I n d}$ due to the spillover effect on an ith unit's variable. Each total parameter is the sum of the corresponding direct and indirect parameters and although we do not observe $c_{i t}^{D i r}, c_{i t}^{I n d}$ and $c_{i t}^{T o t}$ they can be computed using Eqs. 8 - 10. Also, in contrast to, for example, the SAR variable in Eq. 1 one should recognize that $w_{i j}$ does not pre-multiply the observations in Eqs. $8-10$, as in these equations the effect of the spatial weights is incorporated within the estimates of the direct, indirect and total parameters.

As we noted in the opening section, the spatial decomposition of TFP growth in GKPF is strictly a partial extension of the non-spatial decomposition of generalized Malmquist TFP growth in Orea (2002) to the spatial case. More specifically, there is a one-to-one correspondence between the components of the ith unit's TFP growth in the GKPF and Orea decompositions that can be attributed to the $i t h$ unit, which are referred to as direct components in GKPF and are the usual non-spatial components in Orea. There is not, however, a one-to-one correspondence between these non-spatial components in Orea and the indirect components of the $i t h$ unit's TFP growth in GKPF, which account for the effect of spillovers to the $i t h$ unit from the other units in the sample. We therefore develop GKPF to obtain a complete extension of the Orea decomposition to the spatial case and in the following presentation of our decomposition we highlight the terms that we add to the GKPF exposition. We also go one step further as we extend the allocative efficiency growth in the non-spatial TFP growth decomposition in Kumbhakar and Lovell (2000) to the spatial case by including direct and indirect allocative efficiency growth components. By summing these components we obtain the total allocative efficiency change.

We denote spatial total TFP growth as $\triangle T F P_{i t+1, T o}^{T o t}$ and propose a decomposition of this growth into the four total components in Eq. 11:

$$
\Delta T F P_{i t+1, T o}^{T o t}=\Delta T A_{i t+1, T o}^{T o t}+\Delta G V E_{i t+1, T o}^{T o t}+\Delta A E_{i t+1, T o}^{T o t}+\Delta R S E_{i t+1, T o}^{T o t} .
$$

$\Delta T A_{i t+1, T o}^{T o t}$ is the total technical advancement component due to an upward or downward shift in the total frontier when firms experience technical regress or progress. $\triangle G V E_{i t+1, T o}^{T o t}$ captures the impact of a rise or fall in total gross time-varying cost efficiency. $\Delta A E_{i t+1, T o}^{T o t}$ captures the effect of a change in total allocative efficiency and $\Delta R S E_{i t+1, T o}^{T o t}$ represents the contribution of a change in total returns to scale efficiency. As we are interested in TFP growth for the ith unit, the subscript To indicates that spatial total TFP growth and its constituent parts are calculated 
using spillovers that come to the $i t h$ unit from all the $j$ th units. The spatial decomposition of TFP growth in GKPF includes $\Delta T A_{i t+1, T o}^{T o t}$ and $\Delta R S E_{i t+1, T o}^{T o t}$, but whereas they should have included a total efficiency change from the reduced form of their model that is akin to the $\triangle G V E_{i t+1, T o}^{T o t}$ that we include here, they include own efficiency change from the structural model (see Eq. 1 for our structural model), which represents the same efficiency change component as Orea includes in his non-spatial decomposition. The presence of an own rather than a total efficiency change component is the reason why we refer to GKPF as a partial extension of Orea to the spatial case. By introducing $\triangle G V E_{i t+1, T o}^{T o t}$ therefore to the GKPF decomposition our decomposition represents a complete spatial extension of Orea. Also, in line with Orea GKPF do not include an allocative efficiency change component, whereas we further build on these decompositions by including $\triangle A E_{i t+1, T o}^{T o t}$.

We calculate the four total components of $\Delta T F P_{i t+1, T o}^{T o t}$ as follows, where we also show how each of these components can decomposed into their direct and indirect parts. For the underlying mathematical development of the spatial TFP index we use see the Appendix.

1.

$$
\begin{aligned}
\Delta T A_{i t+1, T o}^{T o t} & =-\frac{1}{2}\left(\frac{\partial c_{i t+1}^{T o t}}{\partial t_{i}}+\frac{\partial c_{i t}^{T o t}}{\partial t_{i}}\right) \\
& =-\frac{1}{2}\left[\left(\frac{\partial c_{i t+1}^{D i r}}{\partial t_{i}}+\frac{\partial c_{i t+1}^{I n d}}{\partial t_{i}}\right)+\left(\frac{\partial c_{i t}^{D i r}}{\partial t_{i}}+\frac{\partial c_{i t}^{I n d}}{\partial t_{i}}\right)\right] .
\end{aligned}
$$

2.

$$
\begin{aligned}
\Delta G V E_{i t+1, T o}^{T o t} & =G V E_{i t+1, T o}^{T o t}-G V E_{i t, T o}^{T o t} \\
& =\left(G V E_{i t+1}^{D i r}+G V E_{i t+1, T o}^{I n d}\right)-\left(G V E_{i t}^{D i r}+G V E_{i t, T o}^{I n d}\right) .
\end{aligned}
$$

3.

$$
\begin{aligned}
\Delta A E_{i t+1 . T o}^{T o t} & =\frac{1}{2} \sum_{k=1}^{K}\left[\left(s_{k i t+1}^{T o t}-e_{k i t+1}^{T o t}\right)+\left(s_{k i t}^{T o t}-e_{k i t}^{T o t}\right)\right]\left(p_{k i t+1}^{T o t}-p_{k i t}^{T o t}\right) \\
& =\frac{1}{2} \sum_{k=1}^{K}\left(\begin{array}{c}
{\left[\left(s_{k i t+1}^{D i r}-e_{k i t+1}^{D i r}\right)+\left(s_{k i t}^{D i r}-e_{k i t}^{D i r}\right)\right]\left(p_{k i t+1}^{D i r}-p_{k i t}^{D i r}\right)+} \\
{\left[\left(s_{k i t+1}^{I n d}-e_{k i t+1}^{I n d}\right)+\left(s_{k i t}^{I n d}-e_{k i t}^{I n d}\right)\right]\left(p_{k i t+1}^{I n d}-p_{k i t}^{I n d}\right)}
\end{array}\right) .
\end{aligned}
$$

$\triangle A E_{i t+1 . T o}^{T o t}$ is the change in total input allocative efficiency which occurs when there is a change in one or more of the total input prices and a change in the deviation of the actual total input cost shares from the shares that represent the allocatively efficient total input mix. Multiple outputs give rise to the possibility of similar deviations in the actual total output weights from the total output weights under marginal cost pricing (or equiproportional mark-ups over marginal cost pricing). Kumbhakar and Lovell (2000) note that their presentation of the non-spatial decomposition of TFP growth with multiple outputs is brief because their interest centres on the introduction of allocative efficiency change to the decomposition rather than on the impact of allowing for a higher dimensional output space. In similar vein our interest focuses on augmenting the GKPF decomposition with total allocative efficiency change, which we decompose into its 
direct and indirect parts. In light of this interest we overlook the impact of changes in deviations from the total output weights under marginal cost pricing, which we leave for further work.

In the equations for $\triangle A E_{i t+1 . T o}^{T o t}$ the direct, indirect and total input prices are taken to be $p_{k i t}^{D i r}=p_{k i t}, p_{k i t}^{I n d}=\sum_{j=1}^{N} w_{i j} p_{k j t} \forall i \neq j$ and $p_{k i t}^{T o t}=p_{k i t}+\sum_{j=1}^{N} w_{i j} p_{k j t} \forall i \neq j$. That is to say we compute $p_{k i t}^{D i r}, p_{k i t}^{I n d}$ and $p_{k i t}^{T o t}$ using input price data. $e_{k i t}^{\text {Dir }}, e_{k i t}^{I n d}$ and $e_{k i t}^{T o t}$ are scaled direct, indirect and total input price elasticities and are the allocatively efficient direct, indirect and total input cost shares. The direct, indirect and total input price elasticities from Eqs. $8-10$ are scaled up/down proportionally to sum to 1 because although the structural form of our model in Eq. 1 is characterized by homogeneity of degree 1 in input prices this is not the case for the direct, indirect and total models.

$s_{k i t}^{D i r}, s_{k i t}^{I n d}$ and $s_{k i t}^{T o t}$ are the direct, indirect and total input expenditure share weights which are based on input price and input quantity data. The calculation of $s_{k i t}^{\text {Dir }}$ is based on $p_{k i t} q_{k i t}$, where $q_{k i t}$ is the $k t h$ input quantity. Additionally because in our empirical application we use a specification of $\mathbf{W}_{\mathbf{N}}$ that reflects the systemic nature of the U.S. banking industry by assuming some degree of spatial interaction between all the banks in the sample, $\sum_{j=1}^{N} w_{i j} p_{k j t} q_{k j t}$ is the basis of the calculation of $s_{k i t}^{I n d} \forall i \neq j$. We are therefore taking the reasonable view that the indirect spillover expenditure share for an individual bank is the spatially weighted average of the shares of the other banks in the sample. It follows from the calculations of $s_{k i t}^{D i r}$ and $s_{k i t}^{I n d}$ that the calculation of $s_{k i t}^{T o t}$ is based on $p_{k i t} q_{k i t}+\sum_{j=1}^{N} w_{i j} p_{k j t} q_{k j t} \forall i \neq j$.

4.

$$
\begin{aligned}
& \Delta R S E_{i t+1, T o}^{T o t}=\frac{1}{2} \sum_{m=1}^{M}\left(\begin{array}{c}
{\left[\left(1-\Omega_{i t+1}^{T o t}\right) e_{m i t+1}^{T o t} / \Omega_{i t+1}^{T o t}\right]+} \\
{\left[\left(1-\Omega_{i t}^{T o t}\right) e_{m i t}^{T o t} / \Omega_{i t}^{T o t}\right]}
\end{array}\right)\left(y_{m i t+1}-y_{m i t}\right) \\
& =\frac{1}{2} \sum_{m=1}^{M}\left[\begin{array}{c}
\left(\begin{array}{c}
\left.\left[1-\Omega_{i t+1}^{T o t}\right) e_{m i t+1}^{D i r} / \Omega_{i t+1}^{T o t}\right]+ \\
{\left[\left(1-\Omega_{i t}^{T o t}\right) e_{m i t}^{D i r} / \Omega_{i t}^{T o t}\right]}
\end{array}\right)\left(y_{m i t+1}-y_{m i t}\right)+ \\
{\left[\begin{array}{c}
\left.\left[1-\Omega_{i t+1}^{T o t}\right) e_{m i t+1}^{I n d} / \Omega_{i t+1}^{T o t}\right]+ \\
{\left[\left(1-\Omega_{i t}^{T o t}\right) e_{m i t}^{I n d} / \Omega_{i t}^{T o t}\right]}
\end{array}\right)\left(y_{m i t+1}-y_{m i t}\right)}
\end{array}\right] .
\end{aligned}
$$

$e_{m i t}^{D i r}, e_{m i t}^{I n d}$ and $e_{m i t}^{T o t}$ are the direct, indirect and total elasticities for the $m t h$ output, which we obtain from Eqs. $8-10$, respectively. $\left(1-\Omega_{i t}^{T o t}\right) / \Omega_{i t}^{T o t}$ is the total scale factor, where $1 / \Omega_{i t}^{T o t}=1 / \sum_{m=1}^{M} e_{m i t}^{T o t}$. In Eq. 19 to additively decompose $\Delta R S E_{i t+1, T o}^{T o t}$ into its direct and indirect parts $\left(\triangle R S E_{i t+1}^{D i r}\right.$ and $\left.\Delta R S E_{i t+1, T o}^{I n d}\right)$ we weight the contribution of the change in the direct and indirect output elasticities by the total scale factor.

\section{Data, Variables and the Spatial Weights Matrix}

By estimating Eq. 1 we of course fit a single frontier, but given the diversity of U.S. banks across different size categories we are conscious that the single frontier must be relevant to the banks in the sample. We therefore estimate Eq. 1 for a single U.S. bank size category using a sample of large banks. In doing so we analyze the interaction across the network of large banks net of 
their inter-network interaction with banks in other size categories. ${ }^{11}$

Based on the classification of large U.S. banks in Berger and Roman (2017), we classify a bank as large if it had total assets in 2015 greater than $\$ 3$ billion. The data comprises annual observations for the period $1992-2015$, which is a particularly interesting period as it includes the financial crisis as well sufficiently long pre and post-crisis periods. Furthermore, our data set is a balanced panel because we analyze continuously operating banks to avoid the impact of entry and exit and to focus on the performance of the core group of surviving large institutions.

All the data for the variables was either extracted directly from the Reports of Condition and Income (i.e., the Call Reports) of the Federal Reserve System, which we obtain from the Federal Deposit Insurance Corporation (FDIC), or was constructed by the authors using data from this source. Monetary volumes were then deflated to 2005 prices using the consumer price index. After omitting banks where there is a missing bank-year observation for a variable we are left with a rich sample of 192 large banks. The outputs and input prices are based on the Sealey and Lindley (1977) intermediation approach to banking. In table 1 we describe the variables we use and provide summary statistics for the level variables. All the continuous level variables that are not shares are first logged and then mean adjusted so the first order direct, indirect and total output and normalized input price parameters can be interpreted as elasticities at the sample mean. The three outputs in the model, which reflect the lending and non-lending activities of the banks, are loans $\left(y_{1}\right)$, total securities $\left(y_{2}\right)$ and total non-interest income $\left(y_{3}\right)$. The three input prices relate to the cost of fixed assets $\left(p_{1}\right)$, labor $\left(p_{2}\right)$ and deposits $\left(p_{3}\right)$, where $p_{1}$ is the normalizing input price. We sum the expenditures on the three inputs to obtain the dependent variable total operating cost $(c)$, where $c$ is also normalized by $p_{1}$. The remaining 12 variables in table 1 plus a further variable are $z$ variables from Eq. 1 that may affect banking economic performance. This further variable is a financial crisis dummy variable (2008Dum) which takes a value of 1 in 2008 and thereafter and 0 before.

We take a holistic approach as we focus on identifying changes in spatial TFP growth that can be attributed to various industry-wide phenomena in U.S. banking such as the financial crisis. A more specific approach to the analysis of the interaction between U.S. banks using a subindustrywide specification of linkages between banks to construct $\mathbf{W}_{\mathbf{N}}$ is an area for further work. One possibility to construct a specification of $\mathbf{W}_{\mathbf{N}}$ that is based on subindustry-wide linkages would be to apply the approach of Jaumandreu and Lorences (2002) for Spanish banks to a spatial econometric setting. This would involve using the location of U.S. bank branches from our data source to construct spatial weights for each pair of banks that reflect the bidirectional degree of overlap of the banks' branch networks.

As our interest centres on industry-wide linkages in U.S. banking, the specification of $\mathbf{W}_{\mathbf{N}}$ that we use to estimate our spatial frontier model must account for the entire large bank network. Our specification of $\mathbf{W}_{\mathbf{N}}$ is therefore based on the inverse distance between the zip codes of the headquarters of each pair of large banks. We are therefore taking the view that- the shorter (larger) the distance between banks' headquarters, the greater (smaller) the degree of spatial interaction between the banks, as there is likely to be greater similarity between the impact

\footnotetext{
${ }^{11}$ We thank an anonymous referee for suggesting we focus on a single U.S. bank size category in our application.
} 
of local and regional market conditions for banks with headquarters in close proximity. Since we focus on the large bank size category and use distances between the headquarters of all the banks in our sample to calculate the spatial weights, we use $\mathbf{W}_{\text {All }}^{\text {Large }}$ to denote our specification of $\mathbf{W}_{\mathbf{N}}$. 


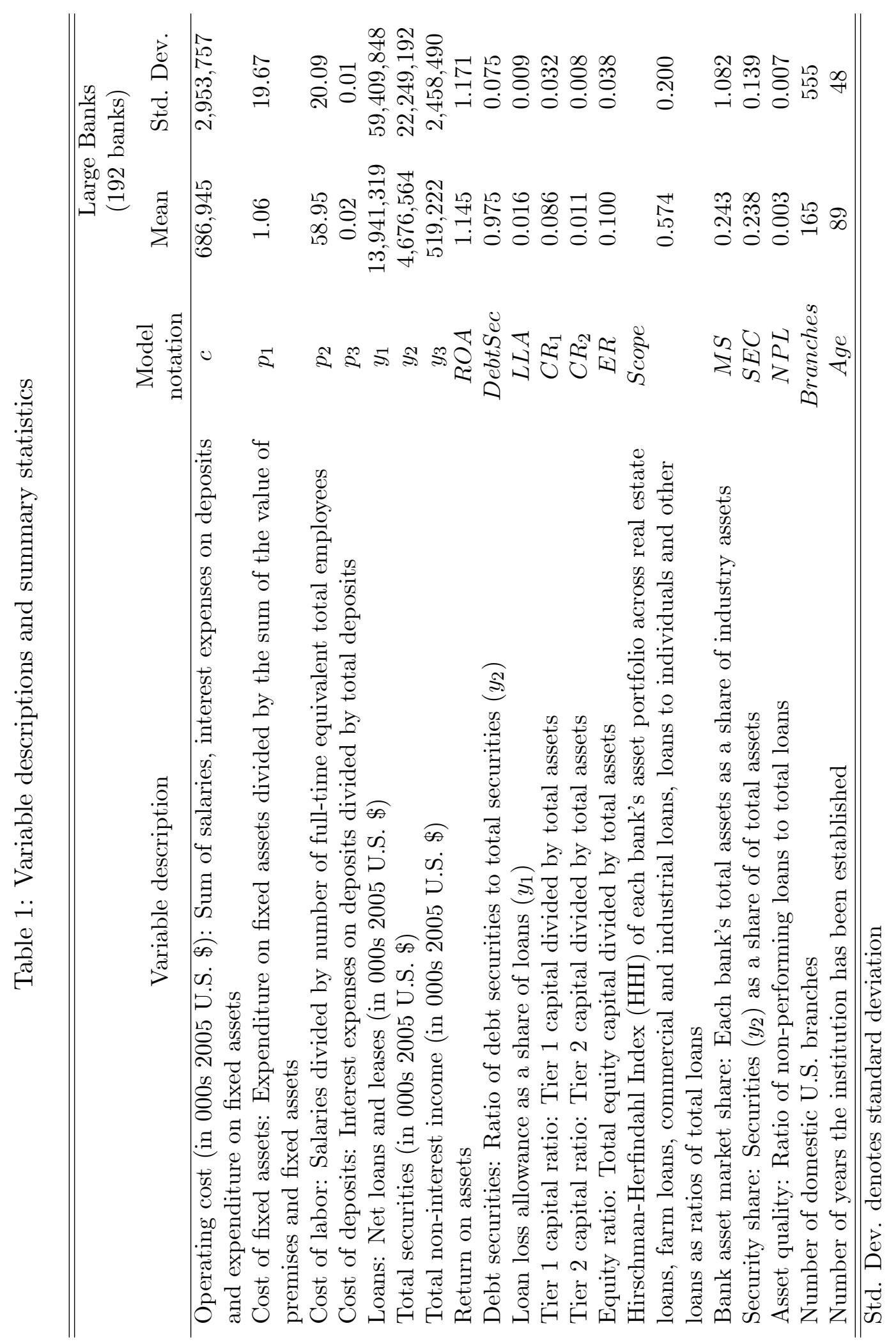


In regional science the analogous $\mathbf{W}_{\mathbf{N}}$ is often used and is constructed using the inverse distances between the centroids of each pair of geographical areas. As geographical areas are exogenous so too are the spatial weights in this type of specification of $\mathbf{W}_{\mathbf{N}}$ in the regional science literature. Here we use the corresponding approach to this type of specification of $\mathbf{W}_{\mathbf{N}}$ in the regional science literature for firm locations. In doing so we follow, among others, Baltagi et al. (2016) who use inverse distances between the locations of the registered addresses of firms to construct their specification of $\mathbf{W}_{\mathbf{N}}$ for their application to Chinese chemical producers. As is the case in their application to chemical producers and also our empirical analysis the spatial weights are exogenous because, although the location of a bank's headquarters is a decision which a bank makes, cost is not a determinant of the location of a bank's headquarters as this would be time-inconsistent. Before a bank can be operational and incur costs it must first settle on the location of its headquarters. ${ }^{12}$

By also row-normalizing our specification of $\mathbf{W}_{\mathbf{N}}$, for a particular bank the SAR observations are a weighted average of the dependent variable observations for all the other banks in the bank's neighborhood set, which preserves the spatial scaling of the data. When a rownormalized inverse distance specification of $\mathbf{W}_{\mathbf{N}}$ is used spillovers are inversely related to the relative distance between the units. Viewing geographical distance as a relative measure allows the interpretation of distance to vary from bank-to-bank depending on how remote or central the location of a bank's headquarters compared to the headquarters of every other bank in the sample. A relative interpretation of geographical distance is particularly appropriate for the banking industry because the financial connectedness of banks ensures that no bank's headquarters are isolated within the banking system.

\section{Results and Analysis for Large U.S. Banks}

\subsection{Estimated Model Parameters}

In table 2 we present the fitted $\mathbf{W}_{\text {All }}^{\text {Large }}$ spatial Durbin stochastic cost frontier (SDCF) model coefficients. ${ }^{13}$ The standard interpretation of the fitted SAR model coefficient, $\delta$, is to recognize that it is not a spillover parameter. Spillover parameters from a model that contains the SAR variable are the indirect parameters, which as is apparent from Eq. 6 depend on, among other things, $\delta$. In table 2 we also present the direct, indirect and total parameters which were computed from the fitted $\mathbf{W}_{\text {All }}^{\text {Large }} \mathrm{SDCF}$ model. An estimate of $\delta$, however, does have an informative interpretation as it represents the degree of SAR dependence across the cross-sectional units. We

\footnotetext{
${ }^{12}$ Data on inter-bank lending is not publicly available but if it was possible to access this data or use some other measure of the financial inter-connectedness of banks it would be possible to construct a financial distance based specification of $\mathbf{W}_{\mathbf{N}}$. Spatial weights based on the financial linkages between banks would, however, be endogenous, which would need to be accounted for. To account for this we would need to replace our estimator in step 1 with an extension of the ML approach that Qu and Lee (2015) propose. Although their estimator accounts for endogenous spatial weights it is for cross-sectional data and would therefore need to be extended to the panel data setting that we consider, which is outside the scope of our paper.

${ }^{13} \mathrm{As}$ is the case with standard non-spatial non-frontier random effects models, the $\log _{10} \vartheta$ parameter in our fitted SDCF model is the weight that is attached to the cross-sectional component of the data. In our fitted $\mathbf{W}_{\text {All }}^{\text {Large }}$ model the $\log _{10} \vartheta$ parameter is significant at the $0.1 \%$ level.
} 
can see from table 2 that the estimate of $\delta$ from the $\mathbf{W}_{\text {All }}^{\text {Large }}$ SDCF model is 0.13 and significant at the $0.1 \%$ level. In the context of the empirical spatial literature a $\delta$ parameter estimate of this magnitude suggests that the SAR dependence across the network of large U.S. banks is non-negligible. Furthermore, table 2 indicates that a number of the fitted model coefficients on the local spatial variables (i.e., the spatial lags of the exogenous regressors) are significant at the $5 \%$ level or lower (e.g., the model coefficients on the $\mathbf{W} y_{3}$ and $\mathbf{W} p_{3}$ variables). For large banks this supports estimation of a spatial Durbin specification rather than the corresponding SAR specification as the latter omits local spatial regressors.

As the direct parameters from our spatial cost frontier can be interpreted in the same way as the parameters from a non-spatial frontier, the monotonicity properties of a non-spatial cost frontier also apply to the direct parameters from our model. We can see from table 2 that all of the first order direct output and input price parameters from the fitted $\mathbf{W}_{\mathbf{A l l}}^{\text {Large }}$ model are positive. In line with production theory, we can therefore conclude that the fitted $\mathbf{W}_{\text {All }}^{\text {Large }}$ SDCF model satisfies the monotonicity property of the translog cost function at the sample mean. Moreover, the reported first order direct output and input price parameters in table 2 are all significant at the $0.1 \%$ level. Based on each of the $y_{1}, y_{2}, y_{3}, p_{2}$ and $p_{3}$ direct elasticity estimates for each individual bank and year, we find for each of these variables that $98 \%$ or more of the elasticities have a positive sign. The direct output and input price elasticities are therefore positive for nearly all of the sample, which suggests that the fitted $\mathbf{W}_{\text {All }}^{\text {Large }}$ SDCF model has good monotonicity properties.

An indirect elasticity measures the effect of the spillover to the ith unit's variable and recall that a total elasticity is the sum of the direct and indirect elasticities. In contrast to direct output and input price elasticities, theory does not predict whether the corresponding indirect and total elasticities should be positive or negative. Table 2 reveals that a number of indirect parameters from our fitted $\mathbf{W}_{\text {All }}^{\text {Large }}$ SDCF are significant at the 5\% level or lower (e.g., the indirect first order $p_{2}, p_{3}$ and $y_{3}$ parameters), which further justifies adopting a spatial approach to cost frontier modeling for large U.S. banks. In particular, at the sample mean the indirect $p_{2}$ elasticity is positive and the indirect $y_{3}$ and $p_{3}$ elasticities are negative. The indirect $p_{2}$ elasticity at the sample mean is positive because the local spatial $p_{2}$ model coefficient (i.e., the model coefficient on the $\mathbf{W} p_{2}$ variable) and the SAR model coefficient are both positive. The indirect $y_{3}$ and $p_{3}$ elasticities at the sample mean are negative because the effect of the negative local spatial $y_{3}$ and $p_{3}$ model coefficients more than offsets the effect of the positive SAR model coefficient. Despite these negative indirect elasticities and some of the indirect output elasticities at the sample mean not being significant, we find for our large bank sample that the direct output and input price elasticities at the sample mean dominate the corresponding indirect elasticities in the calculation of the total elasticities. This is evident from table 2 because in line with the direct output and input price elasticities at the sample mean, all the corresponding total elasticities are positive and significant at the $5 \%$ level or lower. 


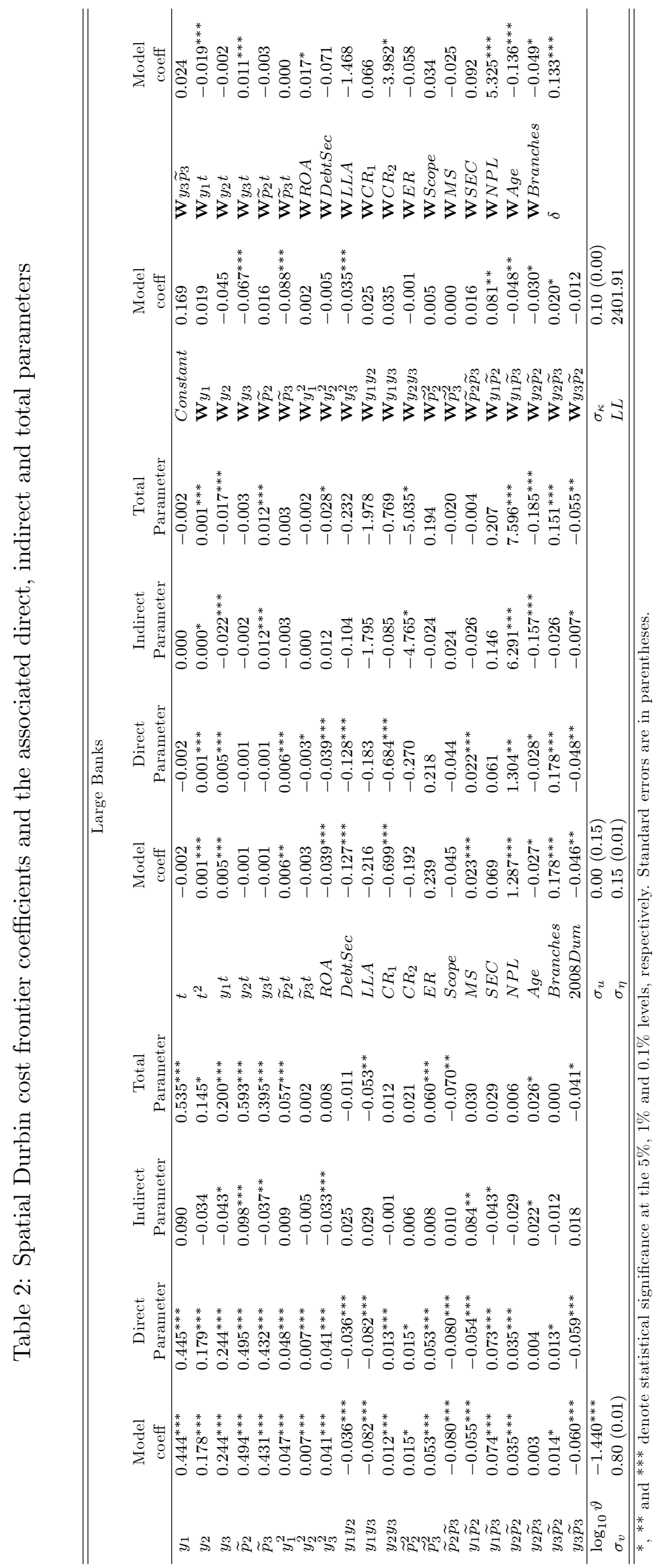


Table 3: Summary own, direct, indirect and total net and gross cost efficiencies for large U.S. banks

\begin{tabular}{lcccccc}
\hline \hline \multicolumn{7}{c}{ Large Banks } \\
& Own NVE & Own NIE & Own GVE & GVE & GVE & \\
& 0.998 & 0.893 & 0.892 & 0.892 & 0.135 & 1.027 \\
Median & 0.998 & 0.883 & 0.881 & 0.883 & 0.134 & 1.016 \\
Mean & 0.000 & 0.058 & 0.058 & 0.058 & 0.005 & 0.059 \\
Std. Dev. & $0.00 E^{\text {Tot }}$ \\
\hline \hline
\end{tabular}

$N V E$ denotes net time-varying efficiency; NIE denotes net time-invariant efficiency; $G V E$ denotes gross time-varying efficiency; Dir denotes direct; Ind denotes indirect; and Tot denotes total.

On one hand the direct first order time parameter fits with our expectations of annual cost diminution for the sample average large bank due to technical progress as this parameter is negative. On the other hand, this parameter does not fit with our expectations as it is not significant so we cannot statistically distinguish this cost diminution from zero. As we will see though for large banks, the direct time elasticities for each bank and year lead to widespread significant annual average changes in the $\Delta T A^{\text {Dir }}$ component of spatial TFP growth. The direct 2008Dum parameter from the $\mathbf{W}_{\text {All }}^{\text {Large }}$ SDCF is also, as we would expect, negative and significant because following the financial crisis interest rates went down which reduced banks' deposit account expenses.

\subsection{Own Cost Efficiencies and Direct, Indirect and Total Gross Cost Efficiencies}

In table 3 we summarize the own NIE, NVE and GVE scores from the fitted structural form

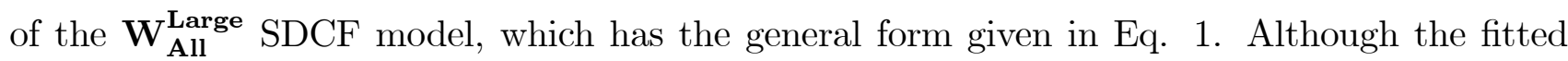

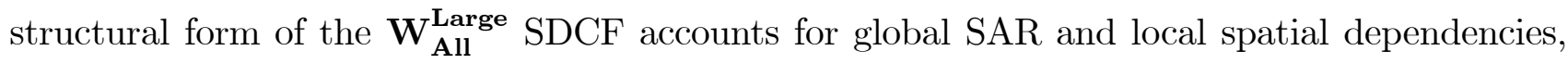
these own efficiencies do not include any form of efficiency spillover. This is in contrast to the direct, indirect and total efficiencies from the reduced form of the fitted model, where we report and analyze these efficiencies for large banks further in this subsection. In particular, direct, indirect and total efficiencies are either partially/entirely made up of an efficiency spillover.

We can see from table 3 for large banks that the sample mean own NIE is 0.883 , whilst the sample mean own $N V E$ is larger and estimated to be 0.998. Multiplying the sample mean NIE and $N V E$ scores for large banks gives the sample mean own $G V E$ of 0.881 . To ascertain whether our fitted $\mathbf{W}_{\text {All }}^{\text {Large }}$ SDCF is characterized by statistically significant inefficiency components we test the model for the presence of $\eta$ and $u$ (i.e., time-invariant and time-varying inefficiencies, respectively). For our sample of large banks we find statistical evidence of the presence of $\eta$ but not $u$ as at nominal levels of significance we reject $H_{0}: \widehat{\sigma}_{\eta}^{2}=0$ but cannot reject $H_{0}: \widehat{\sigma}_{u}^{2}=0$.

When trying to make direct comparisons between our efficiency results and those in the literature one should exercise caution. This is because differences between our results and the findings of other studies can be due to methodological differences as we are the first to apply 
a spatial stochastic frontier model to U.S. banks. We can though draw some parallels between our efficiency results and those reported in other studies. From a methodological perspective the closest non-spatial efficiency analysis of U.S. banks to our study is Tsionas and Kumbhakar (2014). To the best of our knowledge, this is the only other study of U.S. banks to apply a stochastic frontier model with both time-invariant and time-varying inefficiency components. In line with our finding for large banks they report a small mean time-varying inefficiency for their sample of large banks, which is of the order of $3 \%$. They also report a mean time-invariant inefficiency of the order of $3 \%$ for large banks, although one would expect to find more evidence of time-varying and/or time-invariant inefficiency. In line with these expectations, as indicated by our sample mean own NIE score for large banks, we find more evidence of time-invariant inefficiency.

As GVE provides a more complete picture of economic performance than the NIE and $N V E$ measures, we confine our discussion of the direct, indirect and total cost efficiencies from the reduced form SDCF to $G V E^{D i r}, G V E^{I n d}$ and $G V E^{T o t}$. For our sample of large banks we summarize these direct, indirect and total efficiencies in table 3 . We can see from table 3 that the sample mean $G V E^{\text {Dir }}$ for large banks is 0.883 , which is the sample mean own GVE plus efficiency feedback, where this feedback is a particular form of efficiency spillover. Specifically, this feedback is the component of a unit's direct efficiency, which via the spatial multiplier matrix, $\left(\mathbf{I}_{\mathbf{N}}-\delta \mathbf{W}_{\mathbf{N}}\right)^{-1}$, passes through a unit's 1st order and higher order neighbors and rebounds back to the unit. For large banks the magnitude of the sample mean $G V E^{D i r}$ is basically the same as the sample mean own $G V E$ (see table 3), which suggests that there is essentially no efficiency feedback. We can also see from table 3 that the sample mean $G V E^{I n d}$ for large banks is 0.134 , which suggests that the mean sum of the indirect efficiency spillovers that gravitate to a large bank from the other banks in the network is non-negligible. Summing the sample mean $G V E^{\text {Dir }}$ and $G V E^{I n d}$ scores gives a sample mean $G V E^{T o t}$ score of 1.016 for large banks. It is therefore evident that the indirect efficiency spillovers are sufficiently large to push the sample mean $G V E^{T o t}$ score for large banks slightly above the own $G V E$ benchmark of 1 . This idea is more pronounced for the maximum $G V E^{T o t}$ score of 1.103 in our sample, which is well above the own $G V E$ benchmark. Finally, from the kernel density plot of the $G V E^{T o t}$ scores for large banks in figure 2 we can see that the distribution of these scores is not particularly smooth and negatively skewed.

\subsection{Spatial TFP Growth Decompositions}

In figure 3 we present the average annual spatial decompositions of TFP growth for large U.S. banks. In this figure the spatial decompositions of TFP growth are expressed as indices as we take the exponential of the growth rates. There are two aspects to figure 3 , the first is the decomposition of $\triangle T F P^{T o t}$ into $\triangle T F P^{\text {Dir }}$ and $\triangle T F P^{\text {Ind }}$ (panel A). The second is the decomposition of the direct, indirect and total TFP growth rates into direct, indirect and total 


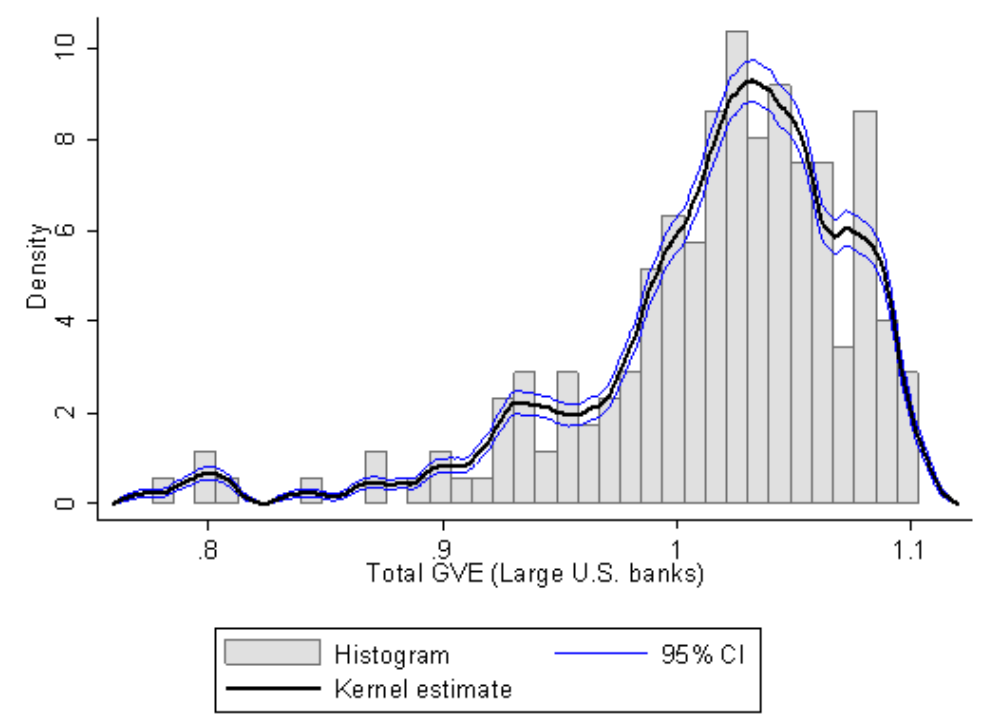

Figure 2: Kernel densities of the total gross time-varying cost efficiencies for large U.S. banks

$T A, G V E, A E$ and $R S E$ growth rates (panels $\mathrm{B}-\mathrm{D}$ ). Panels $\mathrm{A}$ and $\mathrm{D}$ in figure 3 therefore represent two different decompositions of $\triangle T F P^{T o t}$.

According to Berger and Bouwman (2013) the timeline of the 2008 U.S. subprime lending crisis spanned 2007:Q3 - 2009:Q4, which is consistent with the fall in $\triangle T F P^{T o t}$ for large banks in 2007 - 08 in panel A of figure 3. For large banks we can also see from panel A of figure 3 for the second part of our study period that $\triangle T F P^{D i r}$ is a much bigger driver of $\triangle T F P^{T o t}$ than $\triangle T F P^{I n d}$. We can therefore infer from this finding for the sample average large bank that $\triangle T F P^{T o t}$ at the end of the study period is much more dependent on the bank itself (i.e., $\Delta T F P^{D i r}$ ) than on spatial spillovers (i.e., $\Delta T F P^{I n d}$ ). Over the second part of our study period electronic banking became widespread practice leading to, one would think, geography being less important, which is a possible explanation for the marked increase (decrease) that we observe for large banks in the share of $\triangle T F P^{D i r}\left(\triangle T F P^{I n d}\right)$ in $\triangle T F P^{T o t}$ over this period. ${ }^{14}$

For large banks we identify from panels B-D in figure 3 three salient features of the components of $\triangle T F P^{D i r}, \triangle T F P^{I n d}$ and $\triangle T F P^{T o t}$. First, we observe over the study period that a key driver of $\triangle T F P^{D i r}$ is $\triangle T A^{D i r}$ and a key driver of $\triangle T F P^{I n d}$ is $\Delta T A^{I n d} . \Delta T A^{D i r}$ consistently increases with progressively smaller negative changes in the first portion of our study period and $\Delta T A^{\text {Ind }}$ consistently decreases with progressively larger negative changes from $2004-05$ onwards. Although negative SAR dependence is not a frequently observed phenomenon, on the occasions where it is observed it is attributed to the effects of competition between neighbors (Kao and Bera, 2013). On this basis, the declining positive $\Delta T A^{I n d}$ in the first portion of the sample suggests that there has been such a decline in technical diffusion across space that in the second portion of the sample there is negative $\Delta T A^{\text {Ind }}$. In particular, in the second portion of the sample there is increasing negative $\Delta T A^{\text {Ind }}$, which is consistent with increasing geographical technical competition due to, for example, more intense competition between neighboring insti-

\footnotetext{
${ }^{14}$ We thank an anonymous referee for suggesting the growth in electronic banking as a possible explanation for the paths of $\triangle T F P^{D i r}$ and $\triangle T F P^{\text {Ind }}$ for large banks.
} 

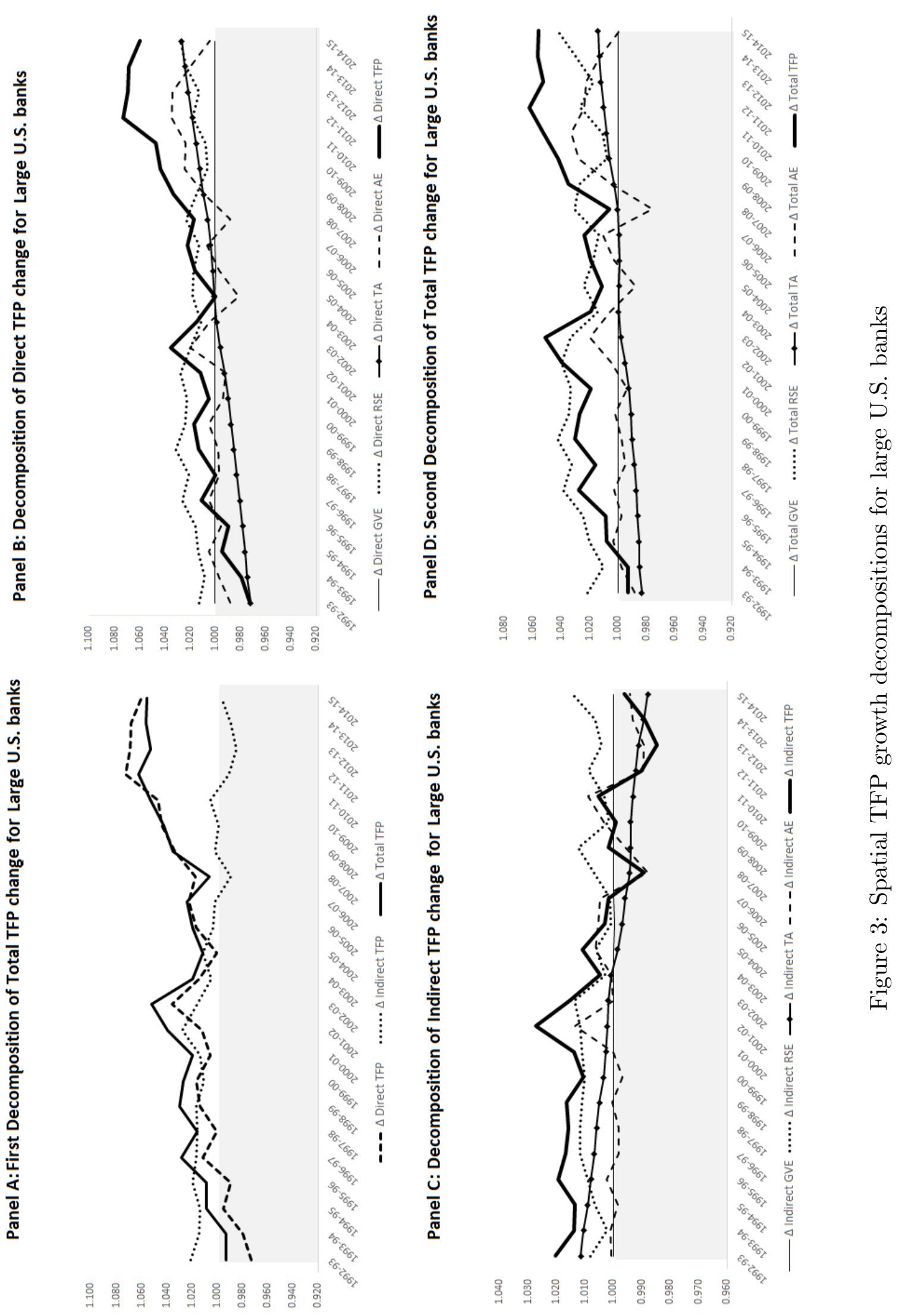
tutions in electronic banking. Second, we find that $\Delta T A^{T o t}$ has an upward trend which reveals that $\Delta T A^{\text {Dir }}$ dominates $\Delta T A^{I n d}$ in the calculation of $\Delta T A^{T o t}$. Third, we can see that over the study period $\triangle T F P^{D i r}$ and $\triangle T F P^{I n d}$ closely track $\triangle A E^{D i r}$ and $\triangle A E^{\text {Ind }}$ and to a lesser extent $\triangle T F P^{T o t}$ tracks $\triangle A E^{T o t}$. For large U.S. banks these findings emphasize the importance of direct allocative efficiency and indirect allocative efficiency spillovers. In terms of direct allocative efficiency we can see that large banks reacted appropriately to the financial crisis as the crisis marked the beginning of a period of year-on-year increases in $\triangle A E^{D i r}$.

We also find statistical evidence to support the above prominent roles of $\Delta T A^{\text {Dir }}$ and $\Delta T A^{\text {Ind }}$ for large U.S. banks. From table 4 we can see that $2004-05$ is the only year where annual $\Delta T A^{\text {Dir }}$ for large banks is not significantly different from 1 over our 23-year sample. Annual $\Delta T A^{\text {Ind }}$ for large banks is also significantly different from 1 for a substantial portion of the sample as table 4 reveals that $\Delta T A^{\text {Ind }}$ is not significant for only four years. Interestingly, these four years are consecutive from 2001 - 02 to $2004-05$. From the same table it is evident that the combined effect of $\Delta T A^{\text {Dir }}$ and $\Delta T A^{\text {Ind }}$ is significantly different from 1 for a large portion of the sample as we observe that annual $\Delta T A^{T o t}$ is not significant for only five years, which are also consecutive $(2003-04$ to $2007-08)$. As annual $\Delta T A^{T o t}$ and $\Delta T A^{D i r}$ for large banks are significantly different from 1 for $2001-02$ and $2002-03$, whilst $\Delta T A^{\text {Ind }}$ is not significant, we can conclude that $\Delta T A^{D i r}$ dominates $\Delta T A^{I n d}$ in these years. Note also that annual $\Delta T A^{T o t}$ is not significantly different from 1 for large banks for $2005-06$ to $2007-08$, whereas $\Delta T A^{D i r}$ and $\Delta T A^{\text {Ind }}$ are significant, which indicates that $\Delta T A^{\text {Dir }}$ and $\Delta T A^{\text {Ind }}$ have offsetting annual effects over this period. Over this period annual $\Delta T A^{\text {Dir }}$ and $\Delta T A^{\text {Ind }}$ for large banks are positive and negative, respectively. ${ }^{15}$

\footnotetext{
${ }^{15}$ For large banks the near linear evolution over the sample period of $\Delta T A^{\text {Dir }}, \Delta T A^{\text {Ind }}$ and thus their combined effect $\left(\Delta T A^{T o t}\right)$ is a pure coincidence and is in no way an artifact of our model.
} 


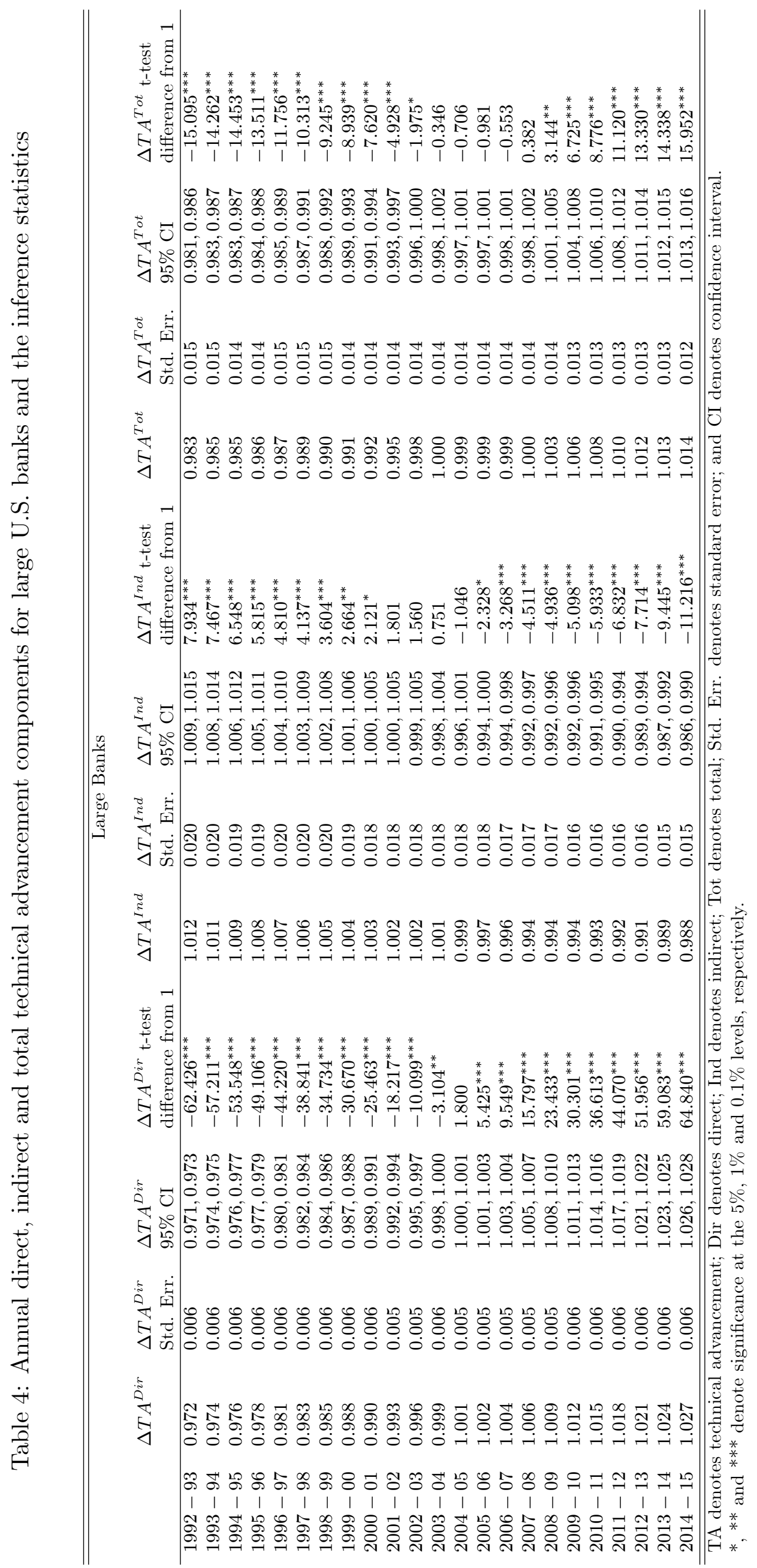




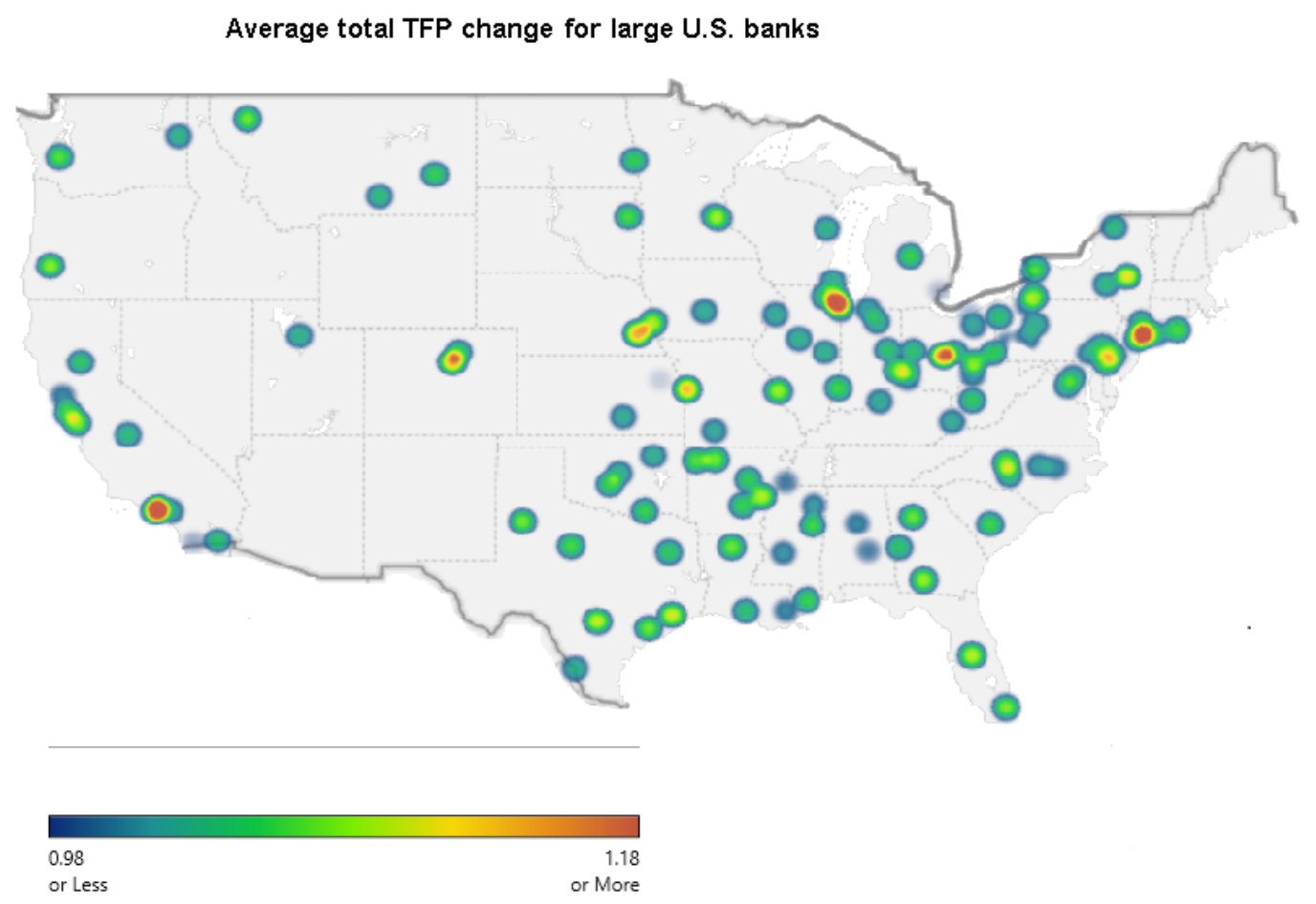

Figure 4: Geographical distribution of average total TFP change over the period 1992-2015 for large U.S. banks

In figure 4 we present the geographical distribution of the average total TFP indices over our sample period. From this figure we can see that there are several clusters of large banks with high average total TFP indices in distinct metropolitan areas (Chicago; Kansas; Los Angeles; Denver; Omaha; Lincoln; and Columbus), where a cluster of banks with high average total TFP indices is represented by a red shaded area. Interestingly, from figure 4 it is evident that New York City is the only case where there are two distinct clusters of large banks with high average total TFP indices in the vicinity of the same metropolitan area.

Finally in this discussion of the spatial decomposition of TFP growth for large banks, we consider the volatility of the direct and indirect components. To this end, as a measure of volatility over the sample period we present for large banks in figure 5 the standard deviations of $\triangle T F P^{D i r}, \triangle T F P^{I n d}$ and their components. The overriding feature of figure 5 is the sharp increase in the volatility of $\triangle T F P^{I n d}$ after the financial crisis in $2010-11$, which we can see is due to a sizeable increase in the volatility of $\triangle A E^{I n d}$. The first observation we make about this finding is that it is an indirect component and not a direct one that exhibits the most volatility in the post-crisis period. This suggests that the main driver of the volatility of the mean spatial TFP growth index for large banks in the post-crisis period relates to inter-bank linkages. Building on this, our second observation sheds light on a possible industrywide linkage to explain this big increase in the volatility of $\triangle A E^{I n d}$ by recognizing that this increase coincides with the post-crisis tightening of U.S. bank regulation, as the Dood-Frank reforms came into being in 2010 . 

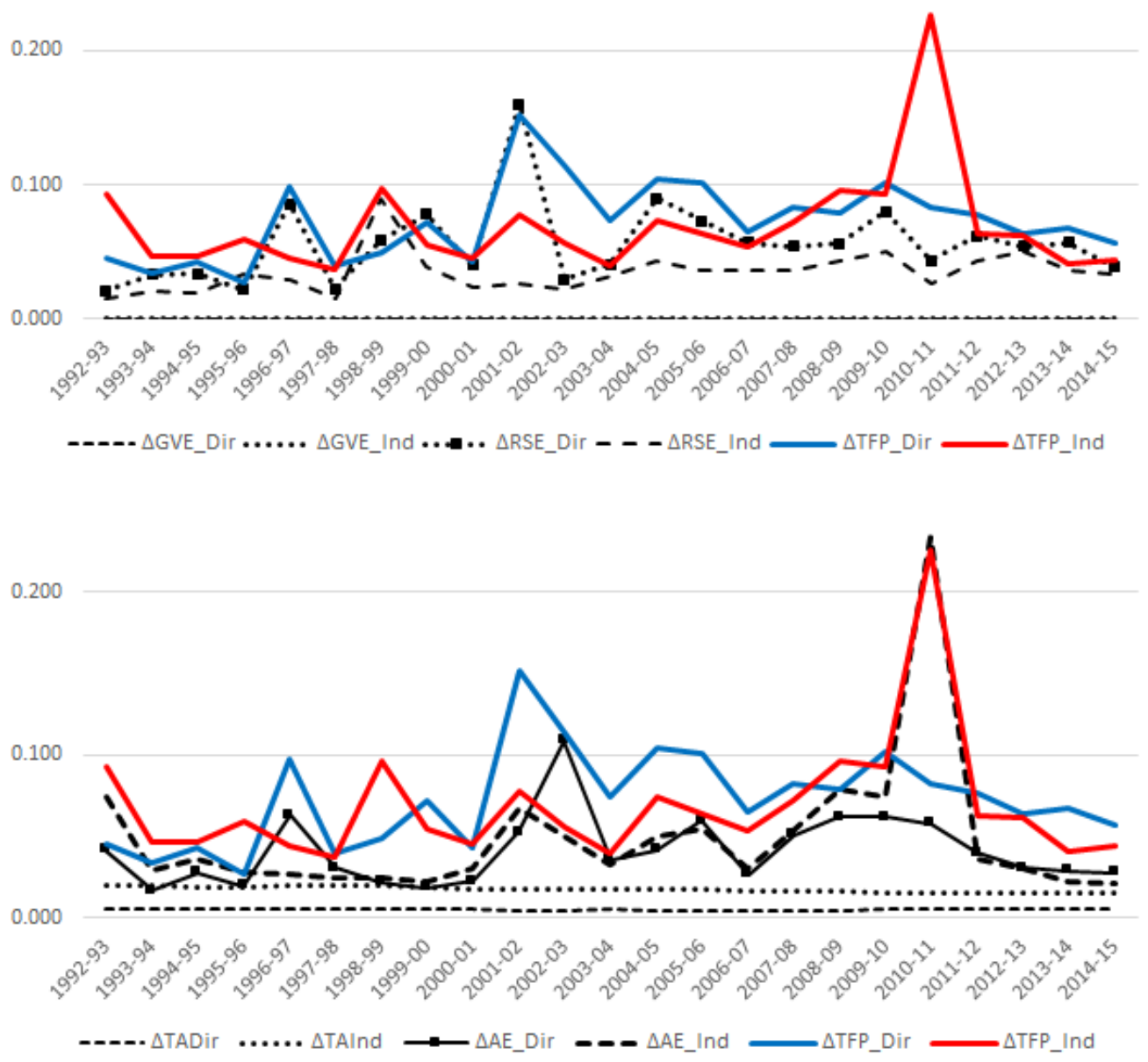

Figure 5: Standard deviations of the components of spatial TFP growth for large U.S. banks 


\section{Concluding Remarks}

In this paper we set out the methodology for a new spatial decomposition of TFP growth. We also demonstrate the steps involved in the practical implementation of our decomposition via an empirical application to large U.S. banks for the period $1992-2015$. As we have highlighted in the paper, although there is a well-developed non-spatial literature on the decomposition of TFP growth and an evolving literature on spatial stochastic frontier modeling, there is just one short study by Glass et al. (2013) (denoted GKPF throughout the paper) on the spatial decomposition of TFP growth. Our paper makes a number of contributions to this sparse literature as we extend GKPF in four varied ways, the first two of which are methodological. First, we introduce a cost efficiency spillover change component to the GKPF decomposition. Second, we augment the GKPF decomposition with own and spillover allocative efficiency growth components. Third, our paper provides a much more detailed coverage of the spatial decomposition of TFP growth than the short GKPF communication. Fourth, whereas the empirical spatial application in GKPF is traditional as they apply their decomposition using data for geographical areas (cities, regions, etc.), we apply our decomposition using firm level data. This suggests that spatial efficiency and productivity analysis can have an important future role in OR. From our empirical application, among other things, we observe for large banks a steady decline in technical diffusion across space in the first part of our sample and increasing geographical technical competition in the second part of the study period.

\section{References}

Anselin, L. (2003): 'Spatial externalities, spatial multipliers and spatial econometrics'. International Regional Science Review, vol. 26, pp. 153-166.

Badunenko, O. and S. C. Kumbhakar (2016): 'When, where and how to estimate persistent and transient efficiency in stochastic frontier panel data models'. European Journal of Operational Research, vol. 255, pp. 272287.

Badunenko, O. and S. C. Kumbhakar (2017): 'Economies of scale, technical change and persistent and time-varying cost efficiency in Indian banking: Do ownership, regulation and heterogeneity matter?'. European Journal of Operational Research, vol. 260, pp. 789-803.

Baltagi, B. H., P. H. Egger and M. Kesina (2016): 'Firm-level productivity spillovers in China's chemical industry: A spatial Hausman-Taylor approach'. Journal of Applied Econometrics, vol. 31, pp. 214-248.

Barth, J. R., R. D. Brumbaugh and J. A. Wilcox (2000): 'Policy watch: The repeal of Glass-Steagall and the advent of broad banking'. Journal of Economic Perspectives, vol. 14, pp. 191-204.

Battese, G. E. And T. J. Coelli (1988): 'Prediction of firm-level technical efficiencies with a generalized frontier production function and panel data'. Journal of Econometrics, vol. 38, pp. 387-399.

BAUER, P. W. (1990): 'Decomposing TFP growth in the presence of cost inefficiency, nonconstant returns to scale, and technological progress'. Journal of Productivity Analysis, vol. 1, pp. 287-299.

Berger, A. N. and C. H. S. Bouwman (2013): 'How does capital affect bank performance during financial crises?' Journal of Financial Economics, vol. 109, pp. 146-176.

Berger, A. N. and R. A. Roman (2017): 'Did saving Wall Street really save Main Street? The real effects of TARP on local economic conditions'. Journal of Financial and Quantitative Analysis. vol. 52, pp. 1827-1867.

Bos, J. W. B., M. Koetter, J. W. Kolari And C. J. M. Kool (2009): 'Effects of heterogeneity on bank efficiency scores'. European Journal of Operational Research, vol. 195, pp. 251-261.

Christensen, L. R., D. W. Jorgenson and L. J. Lau (1973): 'Transcendental logarithmic production frontiers'. Review of Economics and Statistics, vol. 55, pp. 28-45.

Cornwell, C., P. Schmidt And R. C. Sickles (1990): 'Production frontiers with cross-sectional and time-series variation in efficiency levels'. Journal of Econometrics, vol. 46, pp. 185-200.

Coelli, T. J., S. Perelman and E. Romano (1999): 'Accounting for environmental influences in stochastic frontier models: With application to international airlines'. Journal of Productivity Analysis, vol. 11, pp. 251-273. 
Colombi, R., S. C. Kumbhakar, G. Martini and G. Vittadini (2014): 'Closed-skew normality in stochastic frontiers with individual effects and long/short run efficiency'. Journal of Productivity Analysis, vol. 42, pp. $123-136$.

Diewert, W. E. AND K. J. Fox (2017): 'Decomposing productivity indexes into explanatory factors'. European Journal of Operational Research, vol. 256, pp. 275-291.

Druska, V. And W. C. Horrace (2004): 'Generalized moments estimation for spatial panel data: Indonesian rice farming'. American Journal of Agricultural Economics, vol. 86, pp. 185-198.

Filippini, M. And W. Greene (2016): 'Persistent and transient productive inefficiency: A maximum simulated likelihood approach'. Journal of Productivity Analysis, vol. 45, pp. 187-196.

Glass, A. J., K. Kenjegalieva And J. Paez-Farrell (2013): 'Productivity growth decomposition using a spatial autoregressive frontier model'. Economics Letters, vol. 119, pp. 291-295.

Glass, A. J., K. Kenjegalieva And R. C. Sickles (2015): 'Returns to scale and curvature in the presence of spillovers: Evidence from European countries'. Oxford Economic Papers, vol. 68, pp. 40-63.

Glass, A. J., K. Kenjegalieva And R. C. Sickles (2016a): 'A spatial autoregressive stochastic frontier model for panel data with asymmetric efficiency spillovers'. Journal of Econometrics, vol. 190, pp. $289-300$.

Glass, A. J., K. Kenjegalieva, R. C. Sickles and T. Weyman-Jones (2016b): 'The spatial efficiency multiplier and random effects in spatial stochastic frontier models'.

Available at SSRN: https://papers.ssrn.com/sol3/papers.cfm?abstract_id=2873520

Gouriéroux, C., A. Holly And A. Monfort (1982): 'Likelihood ratio test, Wald test, and Kuhn-Tucker test in linear models with inequality constraints on the regression parameters'. Econometrica, vol. 50, pp. 63-80.

Greene, W. H. (2004): 'Distinguishing between heterogeneity and inefficiency: Stochastic frontier analysis of the World Health Organization's panel data on national health care systems'. Health Economics, vol. 13, pp. 959-980.

Greene, W. H. (2005): 'Reconsidering heterogeneity in panel data estimators of the stochastic frontier model'. Journal of Econometrics, vol. 126, pp. 269-303.

Gude, A., I. C. Álvarez And L. Orea (2017): 'Heterogeneous spillovers among Spanish provinces: A generalized spatial stochastic frontier model '. Efficiency Series Paper 2017/03, University of Oviedo, Department of Economics, Oviedo Efficiency Group (OEG).

Jaumandreu, J. And J. Lorences (2002): 'Modelling price competition across many markets (An application to the Spanish loans market)'. European Economic Review, vol. 46, pp. 93-115.

KaO, Y-H. And A. K. Bera (2013): 'Spatial regression: The curious case of negative spatial dependence'. University of Illinois, Urbana-Champaign, Mimeo.

Kelejian, H. H. And I. R. Prucha (1999): 'A generalized moments estimator for the autoregressive parameter in a spatial model'. International Economic Review, vol. 40, pp. 509-533.

Kumbhakar, S. C., G. Lien And J. B. Hardaker (2014): 'Technical efficiency in competing panel data models: A study of Norwegian grain farming'. Journal of Productivity Analysis, vol. 41, pp. 321-327.

Kumbhakar, S. C. And C. A. K. Lovell (2000): Stochastic Frontier Analysis. Cambridge, UK: Cambridge University Press.

Mukherjee, K., S. C. Ray And S. M. Miller (2001): 'Productivity growth in large US commercial banks: The initial post-deregulation experience'. Journal of Banking and Finance, vol. 25, pp. 913-939.

O'D onnell, C. J. (2016): 'Using information about technologies, markets and firm behaviour to decompose a proper productivity index'. Journal of Econometrics, vol. 190, pp. 328-340.

OREA, L. (2002): 'Parametric decomposition of a generalized Malmquist productivity index'. Journal of Productivity Analysis, vol. 18, pp. 5-22.

Orea, L., I. C. Álvarez And T. Jamasb (2018): 'A spatial stochastic frontier model with omitted variables: Electricity distribution in Norway'. Energy Journal, vol. 39, pp. 93-116.

Oude Lansink, A., S. Stefanou And T. Serra (2015): 'Primal and dual dynamic Luenberger productivity indicators'. European Journal of Operational Research, vol. 241, pp. 555-563.

QU, XI. AND L-F. LEE (2015): 'Estimating a spatial autoregressive model with an endogenous spatial weight matrix'. Journal of Econometrics, vol. 184, pp. 209-232.

Schmidt, P. And R. C. Sickles (1984): 'Production frontiers and panel data'. Journal of Business and Economic Statistics, vol. 2, pp. 367-374.

Sealey C., And J. T. Lindley (1977): 'Inputs, outputs and a theory of production and cost at depository financial institutions'. Journal of Finance, vol. 32, pp. 1251-1266.

Sun, K., S. C. Kumbhakar and R. Tveras (2015): 'Productivity and efficiency estimation: A semiparametric stochastic cost frontier approach'. European Journal of Operational Research, vol. 245, pp. 194-202.

Tsionas, E. G. And S. C. Kumbhakar (2014): 'Firm heterogeneity, persistent and transient technical inefficiency: A generalized true random-effects model'. Journal of Applied Econometrics, vol. 29, pp. 110-132.

Tsionas, E. G. And P. G. Michaelides (2016): 'A spatial stochastic frontier model with spillovers: Evidence for Italian regions'. Scottish Journal of Political Economy, vol. 63, pp. 243-257. 


\section{Appendix: Mathematical Development of the Spatial TFP Index}

Orea (2002) provides a non-spatial decomposition of the generalized Malmquist TFP index from a primal parametric output distance frontier and Glass et al. (2013) (denoted GKPF here) partially extend the Orea decomposition to the spatial case of a primal parametric spatial production frontier. We extend GKPF and in doing so obtain a complete extension of Orea to the spatial case for the dual parametric spatial cost frontier. We spatially decompose the generalized Malmquist TFP index into own and spillover components, which using spatial econometrics terminology we refer to as direct and indirect components, respectively. Summing corresponding direct and indirect components gives the associated total component.

We define the generalized Malmquist total TFP index we use, $\triangle T F P_{i t+1, T o}^{T o t}$, as the difference between the rate of change of the total output index, $\Delta Y_{i t+1, T o}^{T o t}$, and the rate of change of the total input quantity index, $\Delta X_{i t+1, T o}^{T o t}{ }^{16}$

$$
\Delta T F P_{i t+1, T o}^{T o t}=\Delta Y_{i t+1, T o}^{T o t}-\Delta X_{i t+1, T o}^{T o t},
$$

where the total output index is the aggregation of the multiple total outputs using the total output elasticities as weights. The observed total input quantity index is measured by $\Delta X_{i t+1, T o}^{T o t}=\Delta c_{i t+1}^{T o t}-\frac{1}{2} \sum_{k=1}^{K}\left(s_{k i t+1}^{T o t}+s_{k i t}^{T o t}\right)\left(p_{k i t+1}^{T o t}-p_{k i t}^{T o t}\right)$ as it is calculated using what we take to be the total price and total cost share for the $k t h$ input from the data $\left(p_{k}^{T o t}\right.$ and $s_{k}^{T o t}$, respectively). Alternatively, the corresponding total input quantity index using allocatively efficient total input cost shares, $e_{k}^{T o t}$, is $\Delta \widetilde{X}_{i t+1, T o}^{T o t}=\Delta c_{i t+1}^{T o t}-\frac{1}{2} \sum_{k=1}^{K}\left(e_{k i t+1}^{T o t}+e_{k i t}^{T o t}\right)\left(p_{k i t+1}^{T o t}-p_{k i t}^{T o t}\right)$. See the discussion of Eq. 16 for details of our approach to compute $p_{k}^{T o t}, s_{k}^{T o t}$ and $e_{k}^{T o t}$.

$\Delta \widetilde{X}_{i t+1, T_{o}}^{T o t}$ is not observed because the allocatively efficient total input cost shares are computed using estimated $c^{T o t}$ elasticities with respect to the input prices. The associated generalized Malmquist total TFP index is given by $\Delta \widetilde{T F P}_{i t+1, T o}^{T o t}=\Delta Y_{i t+1, T o}^{T o t}-\Delta \widetilde{X}_{i t+1, T o}^{T o t}$ and the relationship between $\Delta \widetilde{T F P}_{i t+1, T o}^{T o t}$ and $\Delta T F P_{i t+1, T o}^{T o t}$ from Eq. A1 is:

$$
\Delta T F P_{i t+1, T o}^{T o t}=\Delta \widetilde{T F P}_{i t+1, T o}^{T o t}+\frac{1}{2} \sum_{k=1}^{K}\left[\left(s_{k i t+1}^{T o t}-e_{k i t+1}^{T o t}\right)+\left(s_{k i t}^{T o t}-e_{k i t}^{T o t}\right)\right]\left(p_{k i t+1}^{T o t}-p_{k i t}^{T o t}\right) .
$$

From Eq. A2 we can see that the total input allocative efficiency change component, $\triangle A E_{i t+1, T o}^{T o t}$ (see Eqs. 11 and 16), features in the spatial decomposition of $\triangle T F P_{i t+1, T o}^{T o t}$ because the measures of the observed total input cost shares used to compute $\Delta X_{i t+1, T o}^{T o t}$ differ from the allocatively efficient total input cost shares in the equation for $\Delta \tilde{X}_{i t+1, T o}^{T o t}$.

\footnotetext{
${ }^{16}$ We thank an anonymous referee for providing guidance on the structure of this formal presentation of the spatial TFP index.
} 